\title{
EL CONSENTIMIENTO IMPLÍCITO DESDE LA JURISPRUDENCIA ARBITRAL: COMENTARIOS A LA PRIMERA SECCIÓN DEL ARTÍCULO 14 DE LA LEY DE ARBITRAJE Y ALGUNAS CONSIDERACIONES VINCULADAS \\ IMPLIED CONSENT FROM ARBITRAL JURISPRUDENCE: COMMENTARIES TO THE FIRST SECTION OF ARTICLE 14 OF THE PERUVIAN ARBITRATION LAW AND SOME OTHER RELATED REMARKS
}

\author{
Jorge Alvarado Giraldo* \\ Rodrigo, Elías \& Medrano Abogados \\ Julio Olórtegui Huamán ${ }^{* \star}$ \\ Rodrigo, Elías \& Medrano Abogados
}

The first scenario of article 14 of Legislative Decree 1071 positivizes the theory of the incorporation of non-signatory parties, know internationally as "implicit consent" theory. Although more than twelve years have elapsed since its publication, article 14 has remained disregarded by local pronouncements thus far from the arbitration or judicial levels that could provide us with more elements regarding its application in specific cases.

This article aims to identify the way in which international arbitration tribunals have applied the implicit consent theory to determine what type of conducts throughout the contractual iter have justified the incorporation of a non-signatory to the arbitration. Moreover, the authors seek to provide answers to some questions of substantive and procedural nature: Is the non-signatory jointly and severally liable? How does the incorporation of a non-signatory remain consistent with their right to participate in the constitution of the arbitral tribunal? When should the incorporation of a nonsignatory be decided?

KEYWORDS: Implicit consent; article 14 of the Arbitration Law; non-signatory; active participation; "Group of companies"; international arbitration.
El primer supuesto del artículo 14 del Decreto Legislativo 1071 positiviza la teoría de incorporación de partes no signatarias conocida a nivel internacional como "consentimiento implícito". Si bien ya han transcurrido más de doce años desde su publicación, a la fecha, el artículo 14 no ha sido materia de pronunciamientos locales en el plano arbitral o judicial que nos brinden mayores elementos respecto de su aplicación en casos concretos.

El presente artículo busca identificar la manera en que los tribunales arbitrales internacionales han aplicado la teoría del consentimiento implícito a fin de determinar qué tipo de conductas, a lo largo del iter contractual, han justificado la incorporación de un no signatario al arbitraje. Asimismo, los autores buscan responder algunas preguntas de índole sustantiva y procesal: ¿el no signatario responde de forma solidaria o mancomunada? ¿Cómo se conjuga la incorporación de un no signatario y su derecho a participar en la constitución del tribunal arbitral? ¿En qué oportunidad se debería decidir la incorporación de un no signatario?

Palabras Clave: Consentimiento implícito; artículo 14 de la Ley de Arbitraje; no signatario; participación activa; "grupo de sociedades"; arbitraje internacional.

* Abogado. Ex abogado visitante de Dechert LLP. Profesor en la Universidad de Lima. Asociado senior del Estudio Rodrigo, Elías \& Medrano Abogados (Lima, Perú). Contacto: jalvarado@estudiorodrigo.com.

** Abogado. Ex pasante de Dechert LLP. Vocal del Comité Directivo del Capítulo Peruano del Club Español de Arbitraje. Miembro Fundador de Lima Very Young Arbitration Practitioners. Asociado del Estudio Rodrigo, Elías \& Medrano Abogados (Lima, Perú). Contacto: jolortegui@estudiorodrigo.com.

Nota del Editor: El presente artículo fue recibido por el Consejo Ejecutivo de THËMIS-Revista de Derecho el 29 de abril de 2020, y aceptado por el mismo el 1 de julio de 2020. 


\section{INTRODUCCIÓN}

Bajo el riesgo de espantar a nuestros posibles lectores, tenemos que reconocer que la incorporación de partes no signatarias en el arbitraje no es un tema necesariamente novedoso, ya que este ha sido materia de discusión en la jurisprudencia y doctrina arbitral desde la década de los años 80 , luego de la publicación del laudo del caso Dow Chemical c. Isover Saint Gobain (en adelante, caso Dow Chemical) (1982).

Por su parte, en el Perú, tiene reconocimiento normativo expreso desde el año 2008, en el Decreto Legislativo 1071 (en adelante, Ley de Arbitraje), el cual establece que

el convenio arbitral se extiende a aquellos cuyo consentimiento de someterse a arbitraje, según la buena fe, se determina por su participación activa y de manera determinante en la negociación, celebración, ejecución o terminación del contrato que comprende el convenio arbitral o al que el convenio esté relacionado. Se extiende también a quienes pretendan derivar derechos o beneficios del contrato según sus términos (Decreto Legislativo 1071, 2008, art. 14).

No obstante, transcurridos ya doce años desde la promulgación de la Ley de Arbitraje, a la fecha de elaboración del presente trabajo, se pueden evidenciar pocas fuentes jurisprudenciales o doctrinales en el medio local que nos permitan tener un mejor entendimiento acerca de cómo debe aplicarse la citada disposición.

En materia de jurisprudencia arbitral local, si bien el Centro de Arbitraje de la Cámara de Comercio de Lima ha publicado, a través de su Faro de Transparencia, algunos resúmenes de laudos en los que se analiza la aplicación del artículo 14 de la Ley de Arbitraje, dichos resúmenes no brindan suficiente información para identificar qué tipo de conductas se registraron en cado caso concreto para que se decidiera incorporar o no incorporar al no signatario ${ }^{1}$.

Por su parte, respecto a la jurisprudencia judicial, tenemos "algunas de cal y otras de arena".

Por un lado, contamos con decisiones como la de TSG Perú S.A.C. c. Langostinera Caleta Dorada S.A.C. et al., en donde la Primera Sala Civil con
Subespecialidad Comercial de Lima declaró la validez de un laudo arbitral que había extendido los efectos del convenio a una serie de empresas no signatarias (Expediente 451-2009, 2013). Si bien el laudo en este caso se dictó bajo la vigencia de la anterior ley de arbitraje (por lo que el tribunal arbitral no aplicó el artículo 14), mencionamos esta decisión ya que tanto el tribunal arbitral como la Primera Sala tuvieron en consideración el comportamiento de las no signatarias para emitir su decisión, lo que fue reconocido por los comentaristas ${ }^{2}$ como una decisión positiva en la jurisprudencia nacional respecto a la incorporación de partes no signatarias ${ }^{3}$.

Por otro lado, tenemos decisiones como las del caso Clínica Javier Prado c. Cesar Augusto Ramos Bohorquez et al., que fue decidido por la Segunda Sala Civil con Subespecialidad Comercial de Lima. En este caso, la Clínica Javier Prado solicitó la nulidad del laudo arbitral bajo la causal del literal a) del artículo 63 de la Ley de Arbitraje, alegando que no se cumplían los requisitos para que fuera incorporado al proceso arbitral como parte no signataria bajo el artículo 14 de la Ley de Arbitraje (Expediente 076-2013, 2013).

La Segunda Sala, confirmando el análisis del tribunal arbitral, declaró la validez del laudo al considerar que la Clínica Javier Prado había consentido implícitamente arbitrar al haber participado en la designación del tribunal arbitral y pagado los honorarios del mismo. Esto, pese a que la Clínica Javier Prado señaló en todo momento que tanto la designación del árbitro como el pago de los honorarios se registraban bajo protesta, con la única finalidad de que el arbitraje continúe su curso.

A nuestro entender, esta es una decisión errada ya que no responde a un análisis del consentimiento en el iter contractual -requisito establecido en el artículo 14 de la Ley de Arbitraje- y, en todo caso, no es posible derivar un consentimiento sobre la base de la buena fe, toda vez que la Clínica Javier Prado recalcó en todo momento que su comportamiento se realizaba bajo protesta y no reconoció la competencia del tribunal arbitral.

Es frente a esta falta de referentes jurisprudenciales que preparamos el presente trabajo. Nuestra meta no es realizar un recuento de las distintas teorías sobre la intervención de no signatarios en

\footnotetext{
1 Por ejemplo, ver resumen del Caso Arbitral 204-2016-CCL en Faro de Transparencia (https://www.arbitrajeccl.com.pe/ tipo-de-consultas)

2 Al respecto, nosotros nos reservamos los comentarios a esta decisión para un trabajo posterior.

$3 \quad$ Al respecto, véase Cantuarias (2014).
} 
el proceso arbitral, ni postular una posición sobre los alcances y el contenido de esta norma. Ya existe abundante literatura al respecto ${ }^{4}$.

Nuestro objetivo es revisar los requisitos del primer supuesto del artículo 14 de la Ley de Arbitraje a la luz de la jurisprudencia arbitral internacional ${ }^{5}$ disponible ${ }^{6}$. Ello nos permitirá entender de mejor manera cuál es el estándar aplicado al momento de analizar la incorporación de una parte no signataria sobre la base de su participación en el iter contractual; también cómo se ha aplicado la buena fe en este análisis; $y$, finalmente, cuál es el peso asignado al hecho de que la parte no signataria pertenezca al mismo grupo empresarial que una de las partes signatarias.

Asimismo, este trabajo también abordará preguntas de carácter sustantivo y procesal con respecto a la incorporación de una parte no signataria tales como las siguientes: “¿de qué forma responde una parte no signataria, mancomunada o solidariamente?", “¿puede incorporarse partes no signatarias posteriormente a la constitución del tribunal arbitral?", “¿qué pasa con su derecho de participar en la conformación del tribunal arbitral?", o “¿en qué oportunidad debe un tribunal arbitral resolver la incorporación de una parte no signataria: a través de un laudo parcial o junto con el laudo final?".

\section{II. ¿QUÉ NOS DICE LA JURISPRUDENCIA AR- BITRAL INTERNACIONAL RESPECTO DE LA APLICACIÓN DEL PRIMER SUPUESTO DEL ARTÍ́CULO 14?}

El artículo 14 de la Ley de Arbitraje regula dos supuestos para la incorporación a un arbitraje de una parte no signataria. En primer lugar, cuando sobre la base de la buena fe se pueda determinar que ha existido el consentimiento para arbitrar de todos los involucrados, producto de la participación activa y determinante de la no signataria en el iter contractual. En segundo lugar, cuando existen no signatarios que pretenden derivar derechos $\mathrm{y} / \mathrm{o}$ beneficios de la relación jurídica sometida a jurisdicción arbitral.
Así pues, como adelantamos en la introducción, el presente trabajo únicamente se referirá al primero de los supuestos regidos por el artículo 14 de la Ley de Arbitraje, el cual ha recogido lo que se ha denominado a nivel internacional como la teoría del consentimiento implícito ${ }^{7}$, y agregado expresamente que este consentimiento tiene que ser evaluado a la luz de la buena fe.

Sobre la base de los once laudos arbitrales resumidos en el Apéndice del presente trabajo, a continuación analizaremos los siguientes aspectos en el marco de la aplicación de la teoría del consentimiento implícito:

(i) ¿Cuál ha sido el rol que se le ha dado a la buena fe al analizar la incorporación de una parte no signataria?;

(ii) Durante la etapa de negociación / celebración del contrato ¿qué conductas han justificado (y cuáles no) la incorporación de una parte no signataria?;

(iii) Durante la etapa de ejecución ¿qué conductas han justificado (y cuáles no) la incorporación de una parte no signataria?;

(iv) Durante la etapa de terminación del contrato ¿qué conductas han justificado (y cuáles no) la incorporación de una parte no signataria?; $y$,

(v) ¿Cuál es el peso que se le ha asignado al hecho de que una parte signataria y la parte no signataria pertenezcan al mismo grupo de empresas?

Si bien somos conscientes de que la jurisprudencia arbitral internacional sobre consentimiento implícito -principalmente los laudos de la Cámara de Comercio Internacional (en adelante, $\mathrm{CCl}$ )- no se limita a las decisiones resumidas en el Apéndice antes mencionado, consideramos que estas sí representan un universo importante de la jurisprudencia arbitral internacional disponible sobre esta teoría.

4 Por ejemplo, véanse a Bullard González (2012), Silva Romero (2011), Conejero e Irra (2013), Talero Rueda (2011), o Ramírez (2016).

5 Nos basamos principalmente en la jurisprudencia internacional ya que, como señaló Bullard González, presidente de la Comisión Técnica del Ministerio de Justicia que redactó el Decreto Legislativo No. 1071:

Si uno ve el artículo 14, ese es el otro punto, el artículo 14 no inventa nada, el artículo 14 lo único que hace es recopila los criterios que la jurisprudencia, en varios casos, Dow Chemical, todos los que hemos citado, Thompson... muchísimos casos (2020).

6 La presentada por las publicaciones ICC International Court of Arbitration Bulletin y Yearbook Commercial Arbitration, puestas a disposición por Arbitrator Intelligence.

7 Véanse a Park (2009), Bärtsch y Petti (2013), Born (2014) y Sesin-Tabarelli (2017). Para revisar un análisis de esta teoría basado en los pronunciamientos de varias jurisdicciones europeas, véase a Silva Romero y Velarde Saffer (2018). 
Pese a esto, los comentarios que a continuación presentaremos no deben entenderse de manera restrictiva y tampoco tienen la vocación de ser un manual que deba seguirse a rajatabla para el análisis de la incorporación de partes no signatarias. Más bien suponen ser algunas directrices sobre cómo se ha entendido el tema desde la jurisprudencia.

Así, la única finalidad de estos comentarios es brindar mayores luces con respecto a cómo viene interpretando un sector de la jurisprudencia el consentimiento de un no signatario en virtud de su participación en el iter contractual.

\section{A. ¿Cuál ha sido el rol que ha jugado en la juris- prudencia arbitral internacional la buena fe en el análisis del consentimiento implícito?}

Si bien la jurisprudencia arbitral revisada no menciona expresamente la aplicación de la buena fe como un criterio para el análisis de incorporación de una parte no signataria ${ }^{8}$, creemos que esta sí ha sido considerada de manera implícita en las decisiones antes resumidas $y$, en general, es percibida a nivel internacional como un requisito esencial para la incorporación de una parte no signataria ${ }^{9}$.

De acuerdo con Silva Romero, hablaremos de una interpretación bajo parámetros de buena fe para efectos de la incorporación de una parte no sig- nataria "cuando la conducta de una parte permite inferir su aceptación tácita de los términos de un contrato o permite crear en la otra parte la confianza de que tenía la intención de someterse a los términos del mismo" (2011, p. 58) ${ }^{10}$.

Por lo anterior, consideramos que cuando los tribunales arbitrales hacen énfasis en que el análisis para la incorporación de una parte no signataria pasa por identificar la mutua y real intención de las partes ${ }^{11}$, están aplicando implícitamente un análisis bajo parámetros de buena fe. De esta forma, aquello expresamente previsto en el artículo 14 de la Ley de Arbitraje se condice con la lógica de la jurisprudencia arbitral internacional para la materia concreta y, como tal, puede servir como guía para la interpretación de los operadores del proceso arbitral en el Perú. Así, incluso si el artículo 14 no lo señalara de manera expresa, el análisis del comportamiento durante el iter contractual tendría que darse bajo la óptica de la buena $\mathrm{fe}^{12}$.

B. ¿Qué nos dice la jurisprudencia arbitral internacional con respecto a la participación de un no signatario en la negociación y celebración del contrato?

El rol de los no signatarios en la negociación y/o celebración del contrato ha sido materia de análisis en seis de los once laudos que hemos resumido en este trabajo, no habiéndose encontrado consenti-

8 La única excepción a este comentario es el caso CCI No. 10818. No obstante, el tribunal arbitral no trajo a colación la buena fe en su análisis de incorporación, sino como parte de un comentario respecto al uso que le dio el Tribunal Federal suizo. Al parecer, el reconocimiento de la buena fe por parte del Tribunal Federal suizo como un requisito para incorporar partes no signatarias no se limitaría al caso citado por el tribunal arbitral en el caso CCI No. 10818.

Al respecto, se señala:

Además, sería contrario a las normas de Buena fe, que rigen las relaciones comerciales internacionales, que un individuo que interviene constante y repetidamente en la ejecución de un contrato pueda eventualmente refugiarse detrás de las personas jurídicas que firman el contrato y negarse a estar obligado por las cláusulas que contiene y, en particular, por la cláusula de arbitraje (Tribunal Federal, Caso 4.P.115/2003, 2003, párr. 5.1.1.) [traducción libre].

$9 \quad$ Blessing señala lo siguiente:

Una vez más, el 'corazón' de todas las nociones o doctrinas anteriores es claramente el principio de buena fe, respectivamente el requisito de actuar de buena fe y la noción de que las posiciones o defensas que están en contradicción con las exigencias de actuar de buena fe no merecen protección legal (o arbitral) (1994, pp. 154-161) [traducción libre].

Por su parte, según Born:

En muchos casos relacionados con cuestiones de no signatarios, la atención se centra en las intenciones de las partes. En particular, la atención se centra en las intenciones de las partes - reales o presuntas - de que su acuerdo de arbitraje cumpla los fines para los que dicho acuerdo está diseñado. Esta indagación se repite de diversas formas en la mayoría de las doctrinas jurídicas que se examinan a continuación, y es fundamental para explicar la aplicación de esas doctrinas. Un aspecto de esta investigación es el requisito subyacente en todos los sistemas jurídicos desarrollados de que las partes actúen de buena fe, lo que a menudo afecta a la evaluación de las cuestiones relativas al consentimiento en el contexto de los no signatarios (2014, p. 1415) [traducción libre].

10 Véase también a Ramírez (2016).

11 Véanse los laudos recaídos en los casos citados en este trabajo: CCI No. 4131 (1984), CCI No. 10758 (2000), CCI No. 15116 (2008).

12 Ello, más aún, porque el Código Civil peruano señala expresamente que: "El acto jurídico debe ser interpretado de acuerdo con lo que se haya expresado en él y según el principio de la buena fe" (1984, art. 168). 
miento implícito de las partes en tres $\operatorname{casos}^{13}$ y sí en tres de ellos ${ }^{14}$.

Al respecto es importante señalar que, sobre la base de la jurisprudencia revisada, los tribunales arbitrales no consideran como muestra de consentimiento implícito los siguientes aspectos: (i) la mera participación de una empresa matriz u otra empresa del grupo en las reuniones de negociación; (ii) el envío de correos electrónicos durante esta etapa; (iii) el hecho de haber participado en la votación que conllevó a la aprobación de la firma del contrato; o, (iv) que pese a haber firmado el contrato la ley no permitiera a la parte no signataria celebrar contratos internacionales.

Por otro lado, en al menos tres decisiones, los tribunales arbitrales consideraron como un factor determinante para denegar la incorporación de la parte no signataria el hecho de que las partes aceptaran que, pese a que las empresas matrices u otras empresas del grupo participaron en la negociación del acuerdo para el mejor manejo de sus intereses, terminaron decidiendo no asumir el riesgo correlativo a la relación contractual y, en su lugar, optaron por que dicho riesgo sea asumido por otra empresa vinculada ${ }^{15}$.

Asimismo, hemos evidenciado al menos tres escenarios en los cuales se concluyó que existía un consentimiento implícito para considerar a la no signataria como parte del contrato y del convenio arbitral contenido en este:

- Cuando se acredite que la parte no signataria fue el centro de las negociaciones, no solo dirigiéndolas, sino también asegurándose de contar con alguna participación en los términos del contrato que fue, finalmente, suscrito por otra empresa del grupo.

Esto, por ejemplo, se logra evidenciar en el caso Dow Chemical, en el cual Dow Chemical Francia fue el centro de las negociaciones con las empresas que precedieron a Isover Saint Gobain en los dos acuerdos materia de dicho arbitraje. En dichos acuerdos, además, se establecía que las obligaciones de las partes signatarias podrían ser ejecutadas tanto por Dow Chemical Francia como Dow Chemical Company (ambas no signatarias).
- Cuando se acredite que el representante de la empresa que, finalmente, firmó el contrato no solo tenía un cargo oficial en ésta, sino también en la no signataria, presentándose durante las negociaciones en representación de ambas empresas de forma indistinta.

Esto sucedió en el caso CCl No. 10510 descrito en el Apéndice, en el cual el representante de la Empresa B Francia que negoció el contrato con la Empresa $S$ también ostentaba un cargo formal en $B$ Japón, teniendo este un rol predominante en las negociaciones que llevaron a la firma del contrato.

- Cuando se acredite que la totalidad de las negociaciones se mantuvieron con una empresa (por ejemplo, empresa matriz) y la única razón por la cual el contrato fue firmado por una empresa distinta (por ejemplo, empresa subsidiaria), lejos de buscar escapar de los riesgos de la relación contractual, fue para contar con beneficios especiales.

Esto sucedió en el caso CCI No. 11160 descrito en el Apéndice, en el cual la Empresa MB (matriz de la signataria) manejó exclusivamente las negociaciones y dejó que la signataria firme el contrato de concesión con la única finalidad de beneficiarse de la exoneración al IGV prevista por la ley venezolana.

C. ¿Qué nos dice la jurisprudencia arbitral internacional con respecto a la participación de una parte no signataria en la ejecución del contrato?

El rol de los no signatarios en la ejecución del contrato ha sido materia de análisis en los once laudos que hemos resumido en el Apéndice, no habiéndose encontrado consentimiento implícito de las partes en ocho casos de los descritos ${ }^{16}$ y sí en tres de ellos ${ }^{17}$.

Sobre la base de la jurisprudencia revisada, los tribunales arbitrales no consideran como muestra de consentimiento implícito los siguientes aspectos: (i) ser la empresa cuyas acciones son transferidas por la parte signataria en cumplimiento de un contrato; (ii) la sola calidad de titular de todas

13 Véanse a los casos de este trabajo: CCI No. 5920 (1991), CCI No. 10758 (2000), CCI No. 15372 (2009).

14 Véanse en este trabajo a los casos CCI No. 4131 (1982), CCI No. 10510 (2000) y CCI No. 11160 (2002).

15 Véanse en este trabajo los casos CCI No. 9873 (2000), CCI No. 10758 (2000) y CCI No. 15372 (2009).

16 Véanse en este trabajo los casos CCI No. 5920 (1989), CCI No. 6519 (1991), CCI No. 9873 (2000), CCI No. 10758 (2000), CCI No. 10818 (2001), CCI No. 14208/14236 (2013), CCI No. 15116 (2008) y CCI No. 15372 (2009).

17 Véanse en este trabajo los casos CCI No. 4131 (1982), CCI No. 10510 (2000) y CCI No. 11160 (2002). 
las acciones de la parte signataria; (iii) el tener solo un rol de supervisión del cumplimiento de las obligaciones de la parte signataria; ni (iv) tener una participación incidental como el hecho de enviar un solo correo electrónico durante la etapa de ejecución.

Por otro lado, han sido solo tres los escenarios en los cuales los tribunales arbitrales encontraron el consentimiento implícito en la etapa de ejecución del contrato:

- Cuando existe una provisión específica en el contrato que señala que una parte no signataria específica o todas las empresas de un grupo económico podrán ejecutar las prestaciones del contrato y, en los hechos, son estas partes no signatarias las que efectivamente ejecutan la totalidad de las prestaciones a cargo de las partes signatarias.

Esto sucedió, por ejemplo, en el caso Dow Chemical, en el cual los dos acuerdos de distribución establecían que los equipos podían ser entregados tanto por Dow Chemical Francia como por cualquier otra empresa del Grupo Dow Chemical.

- Cuando parte de los pagos acordados en el contrato son realizados por la empresa matriz (no signataria), sumado a que los representantes de la matriz durante la ejecución del contrato eran los mismos que los de la parte signataria, así como el hecho de que todas las reuniones relevantes se lleven en las oficinas de la matriz y no en las de las subsidiarias.

Eso sucedió, por ejemplo, en el caso $\mathrm{CCl}$ No. 11160, en el cual la Empresa Matriz (no signataria) realizó pagos a cargo de su subsidiaria en la etapa inicial del contrato, tuvo una presencia activa en la ejecución a través de sus representantes (los cuales eran los mismos que los representantes asignados a la subsidiaria) y dirigió la relación entre las partes, al haberse llevado todas las reuniones relevantes en sus oficinas, ubicadas en Londres, pese a que el proyecto se estaba ejecutando en Venezuela.

- Cuando la no signataria ha canalizado todas las comunicaciones entre la contraparte signataria y la empresa matriz signataria. Esto sucedió, por ejemplo, en el caso $\mathrm{CCl}$ No. 10510, en el cual B Japón canalizó el contacto entre la Empresa S y la Empresa B Francia $^{18}$.

Finalmente, consideramos pertinente mencionar tres casos en los cuales, en principio, el tribunal arbitral rechazó la existencia de un consentimiento implícito en la ejecución del contrato. En concreto, son los casos CCl No. 5920, CCl No. 10818 y CCl No. $14208 / 14236$.

En los dos primeros casos, la ley aplicable era la ley suiza, la cual, en concordancia con lo señalado por los tribunales arbitrales que conocieron dichas controversias, no reconocía la posibilidad de que el consentimiento se exprese de forma implícita.

- $\quad$ En el caso CCI No. 5920, la empresa X sostuvo que la empresa BZ debía ser incorporada al arbitraje, pues durante la ejecución del contrato su personal se transfería constantemente a AZ (parte signataria) y viceversa, sin ser posible diferenciarlos.

Al respecto, el tribunal arbitral destacó que si bien en principio este comportamiento podría dar pie a un análisis de participación activa en la ejecución del contrato, en el caso concreto ello no podría interpretarse de buena fe como un consentimiento implícito. Como dimos a conocer anteriormente, en este caso existía una ley que impedía a BZ celebrar contratos internacionales, como lo era el celebrado entre la empresa $X$ y la empresa AZ. De buena fe, no se podría entender que la voluntad de las partes ha sido ir en contra de un mandato legal.

Ciertamente, en un escenario en el que no existiera una norma prohibitiva, consideramos que dicha conducta sería, en principio, un indicio importante para alegar la existencia de un consentimiento implícito.

- $\quad$ En relación al caso CCI No. 10818, la empresa A solicitó la incorporación de la Empresa $C$ en tanto aquella, un año después de la firma del contrato, había pasado a ejecutar la totalidad de las prestaciones a cargo de la empresa B (parte signataria). Además, fue la empresa $C$ la cual estuvo a cargo de

18 Sobre la base de únicamente la información provista por Hanotiau, no compartimos la conclusión del tribunal arbitral. Si comparamos el estándar seguido por otros tribunales arbitrales, sobre todo en el caso Dow Chemical, es difícil encontrar un consentimiento implícito para ser parte del contrato por el solo haber actuado como el canal para las comunicaciones entre las dos partes contractuales, sin haber ejecutado alguna de las prestaciones a cargo de la parte contractual. 
proponer un nuevo acuerdo de distribución exclusiva, sin rastro de la empresa $A$ en la negociación.

A nuestro criterio, de no aplicarse la ley suiza, se debió permitir la incorporación de la empresa $\mathrm{C}$ como una parte no signataria, en tanto que tuvo un rol determinante en la ejecución del contrato (al haber asumido la totalidad de la ejecución de este).

- Por último, tenemos el caso CCI No. 14208/ 14236. Como se explica en el resumen contenido en el Apéndice, en este caso la empresa $A$ inició un arbitraje contra la empresa B y su empresa matriz alegando múltiples teorías. Si bien el tribunal arbitral resolvió incorporar a la empresa matriz en virtud de la teoría del levantamiento del velo societario, su análisis del consentimiento implícito merece un comentario aparte.

En este caso, el tribunal arbitral concluyó que, pese a que la empresa matriz había dejado sin sustancia a la empresa $B$, siendo un mero cascarón y que, en los hechos, era la empresa matriz quien controlaba la totalidad de la ejecución contractual a través de dicho cascarón, no era posible concluir que había existido un consentimiento implícito en tanto que, durante la ejecución contractual, la empresa A nunca remitió comunicación o reclamo alguno a la empresa matriz, siendo que dirigía todas sus comunicaciones a la empresa B.

Esta discusión trae a colación dos temas en concreto: (i) ¿de quiénes se requiere el consentimiento para vincular a una parte no signataria?; y (ii) ¿en qué momento debe haberse brindado este consentimiento?

Con respecto al primer punto, como bien señala el tribunal arbitral en este caso, no se requiere solo el consentimiento de la parte no signataria, sino también el de las partes signatarias. En efecto, el pacto arbitral supone necesariamente un acuerdo entre las partes que lo celebran y, como tal, en el supuesto de que un no signatario deba ser incorporado, es necesario también analizar y determinar -a través de comportamientos- la aceptación de las partes signatarias del mismo. Que el consentimiento sea implícito no obsta a que siga siendo un acuerdo entre partes y, como tal, debe analizarse el comportamiento de las que sí suscribieron el pacto arbitral (a través de su anuencia a la participación del no signatario en la ejecución contractual).

Respecto al segundo punto, este consentimiento no debe brindarse una vez surgida la controversia, sino durante el iter contractual. De lo contrario, por conveniencia, podría alegarse un consentimiento que en los hechos nunca existió.

Analizando esta discusión bajo los parámetros del artículo 14 de la Ley de Arbitraje (en caso hubiera sido aplicable), dado que aquel requiere que el análisis de consentimiento se haga a la luz de la buena fe, podría argumentarse que la empresa matriz sí debió ser parte del arbitraje. Esto en tanto que bajo una óptica de buena fe, podría entenderse que cuando la empresa A remitía comunicaciones a la empresa $B$, en realidad su intención era reclamar a la empresa matriz. Esto tendría sustento en el hecho de que la empresa B era un mero cascarón y, en ese sentido, se encontraba totalmente controlada y subyugada a las decisiones de la empresa matriz.

En esa línea, que la empresa $A$ haya seguido actuando en ejecución del contrato a sabiendas de que la empresa matriz era, en los hechos, su contraparte contractual, en nuestra opinión, también representa un consentimiento implícito de la empresa A para la extensión de lo pactado al no signatario. Dicho consentimiento implícito se ve refrendado no solo con la actuación en ejecución del contrato, sino también con la interposición de la solicitud de arbitraje incluyendo a la empresa matriz. Ciertamente, consideramos más bien contrario a la buena fe que se valide la actuación de la empresa matriz como contraparte en el contrato, pero que no deba responder en el marco de un proceso arbitral por la ejecución que llevó adelante.

D. ¿Qué nos dice la jurisprudencia arbitral internacional respecto a la participación de una no signataria en la terminación del contrato?

El rol de los no signatarios en la terminación del contrato fue materia de análisis solo en tres de los once laudos que hemos resumido en el Apéndice. De estos casos, no se halló el consentimiento implícito de las partes en un caso ${ }^{19}$ y sí en dos de ellos ${ }^{20}$.

\footnotetext{
19 Ver en este trabajo al laudo final del caso CCI No. 10758 (2000).

20 Ver en este trabajo al laudo parcial del caso CCI No. 4131 (1982), así como al laudo parcial del caso CCI No. 10510 (2000). 
Puede concluirse, sobre la base de la jurisprudencia revisada, que los tribunales arbitrales no consideran que el asesoramiento por parte de la matriz (la cual no participó ni en la negociación del contrato ni en su ejecución) hacia su subsidiaria en la resolución de una disputa de gran envergadura represente un consentimiento implícito para arbitrar.

Compartimos esta conclusión. Es razonable que una empresa matriz se interese en los eventuales litigios que una de sus subsidiarias pudiese tener, sobre todo si es una controversia de gran envergadura que podría conllevar a la pérdida o recuperación de millones de dólares pues ello, a su vez, podría recaer en que dicha inversión termine representando una ganancia o una pérdida para el grupo. Por otro lado, no es razonable que se pretenda vincular al arbitraje a una empresa que no ha tenido participación alguna en la negociación o ejecución del contrato y que solo se ha visto involucrada en la etapa final de la vida del contrato brindando solo un rol de asesoramiento.

Por su parte, los tribunales arbitrales han encontrado consentimiento implícito en casos en los cuales, por ejemplo, la decisión de resolver el contrato fue tomada en las oficinas de la subsidiaria no signataria y no por la empresa matriz signataria.

Esto sucedió en el caso CCl No. 10510. La decisión de resolver el contrato de distribución con la empresa $\mathrm{S}$ fue tomada en las oficinas de B Japón (parte no signataria), cuando esta empresa se vinculaba estrechamente con las consecuencias de dicha resolución. Esta decisión podría parecer algo extrema por las mismas razones comentadas anteriormente, la empresa matriz tiene interés en las decisiones que puedan adoptarse con respecto de sus subsidiarias, pues dichas decisiones pueden tener un impacto económico directo en sus resultados. Sin embargo, ello no tendría necesariamente que representar una aceptación para arbitrar, incluso en el supuesto en que la decisión de resolver o terminar el contrato haya sido adoptada en sus oficinas.

Como comentario final, podemos observar que esta es la etapa más difícil del iter contractual para encontrar consentimiento implícito. Esta conclusión no solo parte del menor número de casos en los cuales el comportamiento de una parte no signataria ha sido materia de discusión; sino también por el hecho de que, salvo exista una participación activa y determinante en la negociación o ejecución del contrato, es muy difícil entender, desde un punto de vista económico, que una empresa acepte vincularse solo para la etapa final de la vida de un contrato, dejando de percibir gran parte del beneficio económico y asumiendo el pasivo que representa un posible arbitraje producto de la terminación del contrato.

\section{E. ¿Cuál es el peso que se le ha otorgado a la existencia de un grupo de empresas en el análisis de extensión del convenio arbitral?}

Contrario a lo que muchos lectores podrían esperar, a partir de la revisión de la jurisprudencia resumida en el Apéndice, podemos concluir que la existencia de un grupo de sociedades no es el elemento principal por ponderar para poder incorporar a una parte no signataria.

Como se desprende de un análisis minucioso del laudo Dow Chemical, al cual se le ha atribuido -a nuestro criterio, indebidamente, tal como señala Hanotiau $^{21}$ - el nacimiento de la supuesta doctrina del grupo de sociedades, el elemento esencial para poder vincular a una parte no signataria es la real intención de las partes expresada a través de su participación en el iter contractual ${ }^{22}$. Así, la existencia del grupo de sociedades es un elemento más a tener en consideración en la búsqueda de la intención de las partes, mas no supone ser el el elemento central ${ }^{23}$.

21 Según este autor

es incorrecto decir que el caso de Dow Chemical dio origen a la llamada doctrina del grupo societario. Esta supuesta doctrina no forma parte del estado actual del derecho francés. La referencia a esta doctrina es engañosa. Los tribunales, los árbitros y los principales estudiosos coinciden unánimemente en que la existencia de un grupo de compañías no es por sí misma un elemento suficiente para extender a una empresa no signataria una cláusula de arbitraje firmada por otros miembros del grupo. (Hanotiau, 2011, p. 456) [traducción libre].

22 Al respecto, se señala:

Considerando, en particular, que la cláusula compromisoria expresamente aceptada por algunas de las sociedades del grupo debe obligar a las demás compañías que, contienen dichas cláusulas, y de acuerdo con la intención mutua de todas las partes en el procedimiento, parezcan haber sido verdaderas partes en dichos contratos o haberse visto afectadas principalmente por ellos y por los litigios a que puedan dar lugar $(1984$, p. 136) [traducción libre].

23 Al respecto, se señala:

Considerando que el tribunal determinará, en consecuencia, el alcance y los efectos de las cláusulas de arbitraje en cuestión y, por consiguiente, adoptará su decisión sobre la competencia, teniendo en cuenta la intención común de las partes en este procedimiento, tal como se desprende de las circunstancias que rodean la conclusión y 
De una lectura minuciosa a los laudos que hemos resumido hasta ahora se puede observar que en estos ya se cuestiona la utilidad de la así llamada doctrina del grupo de sociedades ${ }^{24}$. Sin embargo, el laudo que consideramos refleja mejor la posición que actualmente mantiene la jurisprudencia es el laudo del caso CCI No. 11405, el cual señala de manera expresa que

no hay una regla general, en el derecho arbitral Internacional Francés, que disponga que las partes no firmantes de un mismo grupo de compañías se vinculan por una cláusula arbitral, sea siempre o solo en determinadas circunstancias. Lo que es relevante es si todas las partes hayan pretendido vincularse con las partes no firmantes por la cláusula arbitral. No solo las partes firmantes, sino que también las no firmantes lo hayan pretendido (o guiados por las otras partes hayan razonablemente presupuesto esta intención) ser vinculados por la cláusula arbitral ... La literatura legal nos confirma lo que es relevante es si estas partes no firmantes tenían la intención de ser vinculadas, en lugar de una regla general sobre los grupos de compañías: "claramente, no obstante, no es tanto la existencia de un grupo lo que los vincula por el acuerdo firmado por uno de ellos, sino el hecho de que esta fue la verdadera intención de las partes (2006, pie de página 142) [traducción libre].

No obstante, no debe dejar de reconocerse que la existencia de un grupo de sociedades es un factor por considerar -si bien no el principal- en el sentido de que genera ciertas dinámicas en términos de organización, control, participantes comunes en proyectos, el intercambio de miembros o trabajadores del grupo, entre otras situaciones que coadyuvan a identificar el consentimiento de las partes $^{25}$. Tal como se ha desarrollado previamente, la simple existencia de relaciones de empresas de un mismo grupo (matriz-subsidiaria, por ejemplo) no es un parámetro que necesaria o inmediatamente nos deba llevar a la extensión del convenio arbitral a una parte no signataria, pero sí debe ser una causa por analizar para la determinación de la existencia de un consentimiento implícito para arbitrar.

Por lo anterior, concordamos con Hanotiau cuando señala que toda referencia a la doctrina del grupo de sociedades debe desaparecer, debiendo, de esa forma, centrar de nuevo la atención en el criterio principal: el consentimiento ${ }^{26}$.

\section{OTRAS CONSIDERACIONES VINCULADAS A LA INCORPORACIÓN DE PARTES NO SIGNA- TARIAS}

\section{A. ¿Mancomunada o solidaria? ¿De qué forma responden los no signatarios al ser incorpo- rados al arbitraje?}

No es un secreto que en muchos casos la finalidad de solicitar la atracción de una parte no signataria al arbitraje es la de conseguir a un deep pocket que tenga suficiente patrimonio como para asegurar el pago de la totalidad de los montos reclamados.

Pero, ¿que se incorpore a una parte no signataria asegura el poder cobrarle la totalidad de los montos que se reclaman?, casume la no signataria la obligación de pago de forma solidaria o, por el contrario, de forma mancomunada? A fin de responder esta interrogante, tendremos a bien analizar una decisión internacional y una local.

\section{Caso CCI No. 5103 de $1988^{27}$}

En este caso, tres empresas europeas (W, $\mathrm{X}$ e $\mathrm{Y}$ ) fueron creadas por el señor $Z$ (grupo $A$ ) con la fina-

caracterizan el cumplimiento y, posteriormente, la terminación de los contratos en los que aparece. Al hacerlo, el tribunal, siguiendo, en particular, la jurisprudencia francesa relativa al arbitraje internacional, debe tener en cuenta también los usos conformes a las necesidades del comercio internacional, en particular, en presencia de un grupo de empresas (1984, p. 134) [traducción libre].

24 Véanse en este trabajo los casos CCI No. 6519 (1991), CCI No. 9873 (2005), CCI No. 10758 (2000), CCI No. 10818 (2001), CCI No. 11160 (2002), y CCI No. 15116 (2008).

25 Véase lo indicado por Hanotiau:

La así llamada doctrina es mera y extrañamente una inapropiada expresión para el hecho que la conducta puede ser una expresión de consentimiento, parte de todos los elementos del hecho y, sobre todo, de circunstancias que se toman en consideración para determinar si la conducta es relevante para el consentimiento en el caso particular, la existencia de un grupo de compañías puede ser relevante, particularmente porque genera ciertas dinámicas en términos de organización, control, participación común en proyectos, intercambio de miembros del mismo grupo, etc. La referencia a un grupo de compañías en la doctrina es, por lo tanto, innecesaria y no tiene validez por sí misma (2011, p. 456) [traducción libre].

26 Afirma Hanotiau

Yo, por lo tanto, sugeriría que cualquier referencia a un grupo de empresas en la doctrina debería desaparecer de una vez por todas de nuestro vocabulario. Deberíamos volver a nuestros inicios, esto es, a una determinación de los alcances de las cláusulas arbitrales en términos de conceptos y mecanismos básicos (2011, p. 456) [traducción libre].

27 Véase el laudo final del caso CCI No. 5103 (1998). 
lidad de celebrar una serie de contratos para comprar, comercializar y convertir los productos de fosfato vendidos por un grupo de empresas tunecinas (el grupo B). Debido a que las empresas del grupo A no cumplieron con algunas de las fechas de pago acordadas y en adición a ello, tenían reclamos en contra de las empresas del grupo $\mathrm{B}$, la relación entre ambos grupos terminó.

En ese sentido, las empresas del grupo A decidieron demandar al grupo B por incumplimientos contractuales. Por su parte, una vez iniciado el arbitraje el grupo B presentó reconvenciones en contra de los demandantes. Como parte de estas reconvenciones, los demandados reclamaban que las empresas del grupo A respondan conjunta y solidariamente por las facturas impagas que se habían emitido de forma independiente a W, X e Y.

El tribunal arbitral que conoció la controversia concluyó que en este caso se cumplían las condiciones para reconocer la unidad del grupo $A$, siendo que todas las empresas que lo conformaban tuvieron algún tipo de participación durante la negociación, celebración y ejecución de la relación contractual con el grupo B. Así, considerando que la confianza de las relaciones comerciales internacionales exigía que primara la realidad económica del grupo A, ordenó que las empresas que lo conformaban respondan de forma solidaria por las deudas que cada una mantenía con las empresas del grupo $\mathrm{B}^{28}$. Para el tribunal arbitral, el argumento de la confianza de las relaciones comerciales internacionales y la realidad económica del grupo era consistente con el orden público internacional del sistema legal de Francia y Tunes (leyes aplicables al arbitraje) ${ }^{29}$.

Así, cabe cuestionarnos: ¿una solución como esta podría ser adoptada en un arbitraje con sede en Perú? Consideramos que no. El Código Civil es claro al señalar en el artículo 1183 que "la solida- ridad no se presume. Solo la ley o el título de la obligación la establecen en forma expresa" (1984). En ese sentido, como explica el profesor Osterling Parodi, "ante el silencio de las partes, la obligación debe considerarse simplemente como mancomunada" (2007, p. 104).

Es por este mandato legal que, incluso cuando nos encontremos frente a empresas de un mismo grupo, la solidaridad no puede ser presumida, no pudiendo así condenarse de esta forma a las partes no signatarias, salvo que ellas hayan aceptado expresamente dicha forma de pago.

2. Caso No. 2100-2011-CCL de 2014 y decisión de anulación de 2015

En el Perú, el caso Empresa Minera Los Quenaules c. Vena Resources Inc, Vena Perú S.A. \& Azulcochamining S.A.C. (2014) de la Cámara de Comercio de Lima (en adelante, $\mathrm{CCL}$ ), surgió debido a la controversia a raíz de la firma del denominado contrato matriz, mediante el cual Vena Resources le otorgó a Minera Los Quenuales una opción de compra sobre el $51 \%$ de unas concesiones que, a dicha fecha, eran de titularidad de Compañía Minera Las Dunas (posteriormente, Azulcochamining) y que en 2011 fueron transferidas a Vena Perú. A la fecha de firma del contrato matriz, tanto Compañía Minera Las Dunas como Vena Perú eran subsidiarias de Vena Resources.

El tribunal arbitral, invocando el artículo 14 de la Ley de Arbitraje, decidió incorporar al arbitraje a Azulcochamining en conocordancia con el principio de actos propios, fundamentando su decisión dos aspectos: (i) Azulcochamining había generado una confianza legítima a Minera Los Quenuales al hacer suya inicialmente la contestación de demanda de Vena Resources sin oponer objeción alguna al arbitraje (siendo que su primera objeción fue presentada dos años después con el cambio de su

28 Al respecto, se indicó lo siguiente:

Las tres compañías demandantes parecen tener al momento de la conclusión, ejecuciones, inejecuciones y renegociaciones de sus vínculos contractuales con el Grupo EFGH, legítima parte en todos estos contratos por el acuerdo de voluntades de ambos grupos en los procesos. Este análisis se fundamenta, en letra y espíritu, por la tendencia de la famosa y aprobada norma arbitral de reconocer, en circunstancias similares, la unidad del grupo [...] El Tribunal Arbitral es de la opinión que en el presente caso, las condiciones para reconocer la unidad del grupo han sido cumplidas, ya que todas las compañías que forman el grupo han participado, mezclándose genuina y manifiestamente en una relación contractual internacional en donde el conjunto de intereses del grupo prevalece sobre los intereses individuales de cada una de ellas. La seguridad de las relaciones comerciales internacionales demanda que esta realidad económica sea tomada en cuenta y que todas las compañías del grupo sean responsables solidarias por las deudas de las que se han beneficiado directa o indirectamente. [traducción libre].

29 Según Hanotiau:

El tribunal justificó su decisión mediante el requerimiento de seguridad de las relaciones comerciales internacionales. Además, señaló: esta admisión de responsabilidad recíproca solidaria, activa y pasiva en las relaciones entre compañías que pertenecen al mismo grupo está en línea con las posiciones de tomar expresa o implícitamente por todos los demandantes y demandados, con equidad, y no es contrario con ninguna regla de las políticas públicas internacionales de los sistemas legales de Francia y Túnez. (2006, párr. 474) [traducción libre]. 
representación legal) ${ }^{30} ; \mathrm{y}$, (ii) que durante la ejecución del contrato matriz aceptó tácitamente ser parte del esquema contractual a través de comunicaciones enviadas a Minera Los Quenuales ${ }^{31}$.

Sin embargo, lo interesante de la decisión del tribunal arbitral es que, sin mayor sustento ni motivación, señaló que

tanto Azulcochamining como Vena Perú son igualmente obligadas por el daño emergente que Vena [Resources] ocasionó a LQ al incumplir el CM y, por lo tanto, les hace solidariamente responsables del resarcimiento que Vena deberá otorgar a LQ como consecuencia de la emisión del presente laudo (2014, p. 62).

Como era de esperarse, Vena Resources llevó el laudo en cuestión a anulación argumentando que el laudo adolecía, entre otros defectos, de una inexistente motivación respecto a la decisión de ordenar a las partes no signatarias el pago solidario de lo adeudado por Vena Resources (Segunda Sala Civil del Poder Judicial, 2015, Resolución 28).

Al analizar este extremo del recurso de anulación, la Segunda Sala Comercial del Poder Judicial pasó a revisar todas las consideraciones presentadas por el tribunal arbitral para extender el convenio arbitral a Azulcochamining y a Vena Perú. Dentro de ellas se encontraban las siguientes: (i) que las no signatarias fueron en su momento subsidiarias de Vena Resources; (ii) que en momentos distintos de la ejecución del contrato matriz, tanto Azulcochamining como Vena Perú tuvieron titularidad de las concesiones sobre las cuales se había dado una opción de compra y que, por lo tanto, ambas empresas habían tenido alguna relación con los bienes objeto del contrato matriz; y, (iii) que sobre la base de la teoría de los actos propios, Azulcochamining y Vena Perú habían generado una confianza legítima a Minera Los Quenuales de que estas serían partes del arbitraje.
Al resolver el recurso de anulación, la Segunda Sala Civil del Poder Judicial señaló claramente que

no queda claro si la solidaridad derivaría de la aplicación al caso concreto del artículo 14 de la LA o del hecho -afirmado por el tribunal- de haber integrado la relación contractual, ni si esto último deriva a su vez de los actos propios de Azulcochamining o del hecho de pertenecer las tres personas jurídicas a un mismo grupo empresarial (2015, Resolución 28, pp. 63-64).

Consideramos que ninguno de los posibles fundamentos señalados por la Segunda Sala permitiría resolver que las partes no signatarias respondan de forma solidaria en lugar de mancomunada.

En primer lugar, como señalamos al comentar el caso CCl No. 5103, el artículo 1183 del Código Civil requiere que la solidaridad se establezca de manera expresa por la ley o, en su defecto, por el pacto de las partes. Toda vez que el artículo 14 no hace referencia alguna a que las partes no signatarias responden de forma solidaria, dicho artículo, por sí mismo, no puede ser parte del fundamento de un tribunal arbitral para ordenar este tipo de condena. A nuestro criterio, la aplicación de la doctrina de los actos propios y/o el hecho de que las no signatarias sean parte del mismo grupo empresarial que la signataria no merman esta conclusión. En cualquier caso, es necesario diferenciar el ámbito procesal del ámbito sustantivo de la relación jurídica establecida. Que una parte haya mostrado consentimiento implícito para arbitrar no necesariamente conlleva a que esta responda de la misma manera o por todas las obligaciones del contrato. El artículo 14 de la Ley de Arbitraje es una norma de carácter procesal que otorga a la parte la posibilidad de ser incluida en el proceso, mas ello no implica en todos los casos una extensión de todos y cada uno de los efectos o consecuencias contractuales.

30 Al respecto, indicó lo siguiente:

A juicio de este Tribunal, ese es el caso ante el cual nos encontramos en este arbitraje. Así, tal como se desprende de lo señalado en los acápites anteriores, Azulcochamining contestó la demanda arbitral y actuó a lo largo del proceso sin oponerse en forma alguna a su participación en este arbitraje, despertando en LQ la legítima confianza de que aceptaba someterse a los efectos de este arbitraje sin objeción alguna (citado por la Segunda Sala del Poder Judicial, 2015, Resolución 28, pp. 60-61).

31 Se señaló que

por lo demás, la conducta de Azulcochamining con anterioridad al arbitraje era la de una contraparte contractual de LQ, si bien no en el sentido formal (pues no suscribió el CM ni el PA) sí en el sentido material; Así, la participación de Azulcochamining en la ejecución del CM fue tácitamente reconocida por este empresa en carta remitida a LQ con fecha 17 de junio de 2011 (Anexo 1-H de la demanda). En dicha carta, que Azulcochamining envió cuando todavía se denominaba "Vena Perú S.A.". comunicó a LQ que "como empresa subsidiaria de Vena Resources y titular de las concesiones mineras del proyecto azulcocha oeste; entiende que no existe relación obligacional o contractual alguna con su estimada empresa (LQ) (sub. neg. ag.) atendiendo que ello era así porque 'no se ha suscrito ningún nuevo acuerdo y el contrato original venció el pasado 20 de Abril de 2010.' Es decir que Azulcochamining (en ese entonces Ven Perú S.A.) entendía que hasta el 20 de abril de 2010 ella sí se encontraba vinculada por el CM y que habría dejado de estarlo porque precisamente en dicha fecha se habría producido su vencimiento (Empresa Minera Los Quenaules c. Vena Resources Inc, Vena Perú S.A. y Azulcochamining S.A.C., 2015, p. 61). 
En segundo lugar, como es ampliamente reconocido por la doctrina arbitral, los tribunales arbitrales, a diferencia de las facultades con las que cuentan las cortes nacionales, no se encuentran en las posibilidades de integrar la voluntad de las partes ${ }^{32}$. Así, un tribunal arbitral no puede -so pretexto de ser creativo, ni alegando argumentos de justiciacondenar de forma solidaria a las no signatarias a través de una integración contractual, transgrediendo así la legislación peruana.

Como será claro para el lector, la Segunda Sala Civil del Poder Judicial anuló el laudo en este extremo (2015, Resolución 28, p. 66).

\section{B. La incorporación de partes no signatarias y su derecho al trato igualitario en la confor- mación del tribunal arbitral}

Como hemos venido explicando en el presente artículo, la incorporación de partes no signatarias trae consigo sendos problemas de índole procesal. Uno de ellos es la constitución del tribunal arbitral.

Esta problemática es tan antigua como lo es la existencia de arbitrajes con múltiples partes y se puede observar en la saga del caso $B K M I$ Industrienlagen $\mathrm{GmbH}$ \& Siemens AG c. Dutco Construction (en adelante, caso Dutco). En esta, la Corte de Casación de París anuló el laudo arbitral dictado en el caso CCl No. 5836 (1989) bajo el argumento de que se había dado una indebida constitución del tribunal arbitral (Caso No. 89-18708 8918726, 1992).

En concreto, Siemens, BKMI y Dutco firmaron un contrato de consorcio en 1981 para la construcción de una planta de cemento en Sultanato de Omán. Tiempo antes de iniciar el proyecto, surgió una disputa dentro del consorcio, por lo cual Dutco inició un arbitraje administrado por la $\mathrm{CCl}$ contra las otras dos consorciadas. Al conformar el tribunal arbitral, Dutco designó a su árbitro y la $\mathrm{CCl}$ determinó que las otras consorciadas tenían que designar a un árbitro de forma conjunta, lo cual hicieron bajo protesta. Emitido el laudo, Siemens y BKMI presentaron una solicitud de anulación de laudo con el argumento de que su derecho al trato igualitario en la designación de los árbitros se había vulnerado. Estas alegaron que a diferencia de Dutco, ellas no pudieron designar a un árbitro de forma independiente y fueron obligadas a designar un árbitro de forma conjunta pese a tener intereses contrapuestos

La decisión de la Corte de Casación francesa en el caso Dutco llevó a que la $\mathrm{CCl}$ conformara un grupo de trabajo sobre arbitrajes multiparte ${ }^{33}$, el cual dio lugar a las modificaciones recogidas en su Reglamento de Arbitraje de 1998, el que establece en el artículo $10^{34}$ que en arbitrajes en los que una de las partes esté conformada por más de una persona, era necesario que dicho conjunto designara de manera consensuada a un árbitro; caso contrario, la Corte de Arbitraje sería la encargada de designar a la totalidad del Tribunal Arbitral.

Si bien esta nueva regulación solucionaba el problema de la incorporación de no signatarios previamente a la constitución del tribunal arbitral, no lo hacía respecto a la incorporación de no signatarios posteriormente a este hito.

Esta problemática se observa en un caso arbitral ad hoc no público citado por Hanotiau, en el cual la demandante solicitó la incorporación de tres partes no signatarias como demandadas posteriormente a la constitución del tribunal arbitral. En este caso, al rechazar su incorporación al arbitraje, las demandadas no signatarias señalaron que, como el tribunal arbitral ya había sido constituido, se les había privado de su derecho de participar en su conformación. Dentro de los argumentos para aceptar la incorporación de las partes no signata-

32 En Himpurna California Energy Ltd c. PT (Persero) Perusahaan Listruik Negara se indicó lo siguiente:

Los árbitros no pueden usurpar el rol de los oficiales del gobierno o líderes empresariales. Ellos no tienen autoridad política, y no tienen derecho a imponer su visión personal en lo que puede ser una apropiada solución negociada. Sin importar la pureza de sus intenciones, los árbitros que actúen de esta manera estarían abandonando sus labores, y crearían más maldad que bien. El foco de atención de un Tribunal Arbitral es de comprobar los derechos y obligaciones de las partes en las particulares disposiciones del contrato por la cual deriva su autoridad (1999) [traducción libre].

33 Véase Voser (2009, p. 392).

34 Según el Reglamento de Arbitraje de la Cámara de Comercio Internacional (en adelante, $\mathrm{CCl}$ )

Donde haya múltiples partes, ya sea como demandante o demandado, y donde la disputa deba remitirse a tres árbitros, los múltiples demandantes, en conjunto, y los múltiples demandados, en conjunto, designarán un árbitro para su confirmación conforme al artículo 9.2. En ausencia de dicha denominación conjunta y cuando todas las partes no puedan unirse para acordar un método para la Constitución del Tribunal Arbitral, El Tribunal podrá nombrar a cada miembro del Tribunal Arbitral y designará a uno de ellos para que actúe como presidente. En ese caso, el Tribunal tendrá la libertad de elegir a cualquier persona que sea adecuada para actuar como el árbitro, aplicando el artículo 9 , cuando este sea considerado apropiado (1998, art. 10) [traducción libre]. 
rias, el tribunal arbitral (i) tomó en consideración que las empresas no signatarias y la demandada signataria se habían comportado como un consorcio o asociación de empresa frente a la demandante y que, por lo tanto, se les debía considerar como una misma parte; $y$, (ii) que, en realidad, estas no presentaban intereses contrapuestos, por lo que se había respetado su derecho a designar a un árbitro (Hanotiau, 2006, pp. 206-207, párr. 457)

Hoy en día esta problemática ha sido abordada y resuelta por muchos centros arbitrales a nivel internacional ${ }^{35} \mathrm{y} \mathrm{local}^{36}$. De acuerdo con esta regulación, no se podrá incorporar partes no signatarias al arbitraje de forma posterior a la designación o confirmación de un árbitro salvo que todas las partes, incluyendo a la no signataria, den su consentimiento. Al requerir el consentimiento de la no signataria, se está respetando su derecho a participar en la constitución del tribunal arbitral.

No obstante, distinto es el caso en los arbitrajes ad hoc o administrados por centros arbitrales cuyos reglamentos no contemplan reglas al respecto. Al respecto, Conejero propone hasta cuatro posibles soluciones para los casos de late joinder o incorporación de no signatarias con posterioridad a la constitución del tribunal arbitral.

- Una primera solución es no permitir, bajo ningún supuesto, la incorporación de no signatarios posteriormente a la designación o confirmación de un árbitro. Esta solución buscaría evitar cualquier posibilidad de que se cuestione el laudo arbitral por vulneración del principio de igualdad de en la designación del tribunal arbitral (Conejero, 2009, p. 427).

- Una segunda solución es permitir el late joinder solo en los casos en que exista acuerdo expreso de todas las partes, incluyendo a los no signatarios. Esta solución, como se- ñalamos antes, es la que actualmente han adoptado, por ejemplo, la CCl y la CCL. El problema con este enfoque es que si existiera una oposición a la incorporación del no signatario por cualquiera de las partes, no se podrá proceder con su incorporación. En aquel caso, será irrelevante si no se cumplen todos los requisitos previstos en el artículo 14 de la Ley de Arbitraje ${ }^{37}$, o si la incorporación del no signatario es la única forma en que el arbitraje cumpla con su finalidad.

Debe decirse que aquello es, quizás, la mayor desventaja del proceso arbitral frente a un proceso judicial. En efecto, existirán supuestos en los cuales para que el proceso pueda cumplir su finalidad deban incorporarse a no signatarios o cuyos convenios arbitrales son independientes -incluso, bajo administración y reglas distintas-.

En un proceso judicial, la autoridad jurisdiccional a cargo podrá -de oficio o a pedido de parte- integrar la relación jurídica procesal en aras de salvaguardar su validez y la eficacia de la resolución final que se emita. Ciertamente, las reglas de acumulación subjetiva de pretensiones buscan asegurar dicha finalidad.

Sin embargo, el proceso arbitral como mecanismo heterocompositivo de resolución de conflictos resulta una excepción a la jurisdicción regular que requiere de la existencia de una voluntad manifestada para someterse a este. Así, podrían registrarse problemas cuando una de las partes del proceso no ha suscrito el convenio arbitral, pero por razones de índole sustantivo su participación es necesaria.

Por ejemplo, desde nuestra experiencia, conocemos de un caso en el que se venía

35 La Cámara de Comercio Internacional señala en su reglamento:

La parte que desee incorporar una parte adicional al arbitraje deberá presentar su solicitud de arbitraje en contra de la parte adicional (la "Solicitud de Incorporación") a la Secretaría. Para todos los efectos, la fecha en la que la Solicitud de Incorporación sea recibida por la Secretaría será considerada como la fecha de inicio del arbitraje contra la parte adicional. Toda incorporación estará sujeta a las disposiciones de los Artículos 6(3)-6(7) y 9. Ninguna parte adicional podrá ser incorporada después de la confirmación o nombramiento de un árbitro, salvo que todas las partes, incluyendo la parte adicional, acuerden lo contrario. La Secretaría podrá fijar un plazo para la presentación de la Solicitud de Incorporación (2017, art. 7.1).

36 El Reglamento de la Cámara de Comercio de Lima indica:

Con posterioridad a la constitución del Tribunal Arbitral, la incorporación procede solo si las partes, incluyendo la parte adicional, así lo acuerdan y el Tribunal Arbitral acepta dicha solicitud (la "Solicitud Conjunta de Incorporación"). Para estos efectos, toma en consideración la necesidad o la conveniencia de que las disputas con la parte adicional sean resueltas dentro del mismo arbitraje, el estado de avance del proceso arbitral y otras circunstancias que estime relevantes (2017, art. 8.4).

37 Véase a Conejero (2009, p. 427). 
construyendo la ampliación de una planta industrial en la que participaban diversos contratistas. En el marco de dicho proyecto, todos los contratistas contaban con contratos independientes con el dueño de la obra, e incluso los convenios arbitrales poseían distinta naturaleza. Lamentablemente, durante la ejecución de la obra se produjo un accidente causado en mayor o menor grado por varios de los contratistas.

Para lograr el resarcimiento de los daños causados, era necesario iniciar un proceso multiparte contra todos los involucrados, pero el convenio arbitral individual suscrito con cada uno de ellos hacía ello imposible. Sin embargo, en el marco de los procesos individuales que se tramitaran, necesariamente tendría que analizarse el grado de responsabilidad de contratistas que no fungían como demandados. Más aún, el riesgo de pronunciamientos contradictorios -otra de las razones que sustentan la acumulación de pretensiones- era muy alto ante la obligación de tramitar procesos independientes.

Fuera de la discusión conceptual sobre la manera en que responderían todos los involucrados como co-causantes del daño (mancomunada o solidariamente), lo cierto es que la fórmula de resolución de conflictos adoptada para un caso como este no aseguraba la efectiva tutela jurisdiccional de las partes.

Se trata de un problema que en estas circunstancias no parece ser solucionado de alguna manera distinta al consentimiento de todas las partes para someterse a un proceso arbitral único, lo cual resulta, en la práctica, utópico. Ello debido a que, ante la interposición de una demanda bajo un convenio arbitral que incluya a un tercero que no lo suscribió, probablemente se formularía un fundado cuestionamiento a la jurisdicción. Por su parte, el inicio de un proceso judicial contra los involucrados también probablemente terminaría con la formulación de una fundada excepción de convenio arbitral.

En esas condiciones, si bien ello debe ser previsto ex ante durante la negociación de este tipo de contratos (por ejemplo, conside- rando un único tipo de convenio arbitral o fijando desde el inicio un consentimiento para la participación de un grupo determinado de personas en un eventual proceso arbitral), lo cierto es que no existe en principio forma alguna para conminar a todas las partes a la participación de un proceso arbitral ${ }^{38}$.

- Una tercera solución es permitir que el tribunal arbitral decida a su solo criterio si se incorpora o no a la no signataria (2009, pp. 354-366). Esta solución es la más peligrosa debido a que deja abierta la posibilidad de que la parte no signataria pueda, luego del dictado del laudo, cuestionarlo por haberse violado su derecho a igualdad en la constitución del tribunal arbitral.

- La última solución, tomada por Conejero de la propuesta de la profesora Voser, es que una vez incorporada la parte no signataria, se reconstituya el tribunal arbitral para garantizar, de ese modo, el derecho de igualdad de las partes en la constitución del tribunal arbitral (2009, p. 428). De acuerdo con la propuesta de la profesora Voser, esta última solución podría aplicarse a los casos en que no se ha podido solicitar la incorporación de la parte no signataria de forma previa debido a que una de las partes había ocultado información cuando, además, existan intereses contrapuestos entre la parte signataria y la otra empresa con quien, en principio, debería designar conjuntamente un árbitro (2009).

Frente a la falta de regulación, los tribunales arbitrales deberán necesariamente ser cuidados con la solución que adopten, sobre todo considerando el deber intrínseco de emitir un laudo válido y ejecutable.

\section{Oportunidad de la decisión respecto al pedido de incorporación de una parte no signataria ¿Debe darse mediante un laudo parcial $o$ a través del laudo final?}

Hoy en día no es discutido que los tribunales arbitrales pueden emitir tantos laudos como estimen pertinentes, pudiendo resolver objeciones jurisdiccionales a través de los denominados laudos de jurisdicción, esto es, ante supuestos en que se hubiera determinado la bifurcación del proceso arbitral.

38 Ante ello, una solución práctica podría consistir en que el convenio arbitral recoja la autorización a las partes al inicio de un proceso judicial para los casos en los que sea necesario incorporar a terceros no signatarios y la imposibilidad de continuar con un proceso arbitral haya sido determinada previamente en dicha vía. Dicha previsión tendría que ser interpretada siempre dentro de los alcances de la buena fe contractual, a efectos de evitar que sea utilizada como una válvula de escape a la jurisdicción arbitral. 
En este sentido, la pregunta que surge es ¿qué requisitos deben cumplirse para que el tribunal arbitral decida bifurcar el arbitraje y resolver la solicitud de incorporación de parte no signataria a través de un laudo de jurisdicción y no a través del laudo final?

Al respecto, en el caso $\mathrm{CCl}$ No. 4402, el tribunal arbitral identificó 4 principales condiciones para resolver la incorporación de una parte no signataria a través de un laudo de jurisdicción en un procedimiento bifurcado:

- Que las discusiones materia del análisis de jurisdicción sean claramente separables del resto de los puntos controvertidos;

- Que las partes hayan tenido la posibilidad de presentar su caso respecto a la discusión de jurisdicción;

- El laudo parcial será útil para resolver las cuestiones pendientes; así como,

- La urgencia de resolver este punto (1982, párr. 4).

Estas condiciones reconocidas jurisprudencialmente se encuentran en concordancia con lo señalado por la doctrina arbitral, la cual requiere que, para poder bifurcar un arbitraje en etapa de jurisdicción y de méritos, la discusión de jurisdicción debe ser claramente separable de la discusión de fondo ${ }^{39}$, no existiendo riesgo de adelanto de opinión ${ }^{40}$.

En este sentido, como reconoce el tribunal arbitral en el caso $\mathrm{CCl}$ No. 4402, la decisión de incorporación de partes no signatarias es un escenario clásico para la emisión de un laudo de jurisdicción, en tanto que (en la mayoría de los casos) puede ser claramente separado del fondo de la controversia ${ }^{41}$. Asimismo, en aquellos casos en los cuales la objeción esté debidamente sustentada, será incluso más imperativo que el tribunal arbitral emita un laudo de jurisdicción. Esto en el sentido que le evitaría a la supuesta parte no signataria los costos de tener que defenderse en un arbitraje para el cual nunca dio su consentimiento ${ }^{42}$.

Esta situación puede variar, por ejemplo, en caso la teoría que se invoque sea la del levantamiento del velo societario, en la cual las cuestiones de jurisdicción y fondo suelen estar estrechamente vinculadas. En esos casos, es conveniente que el tribunal arbitral permita a las partes presentar su caso tanto en jurisdicción como en fondo para decidir ambas cuestiones a través de un mismo laudo, evitando así el adelanto de opinión.

\section{COMENTARIOS FINALES}

El presente trabajo ha tenido como única finalidad brindar mayores luces respecto a la aplicación de la primera sección del artículo 14 de la Ley de Arbitraje (teoría del consentimiento implícito) a la luz de la jurisprudencia arbitral internacional, base sobre la cual fue redactado. Si bien aún queda mucha jurisprudencia arbitral por comentar y analizar -esperamos poder abarcarla en futuros trabajosterminamos el presente artículo con la esperanza de haber logrado nuestro principal cometido: aterrizar casos concretos para los a veces nebulosos requisitos establecidos en el primer supuesto del artículo 14.

Solo la futura jurisprudencia arbitral local -arbitral y judicial- nos podrá confirmar esto. Estaremos

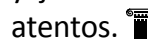

39 Como Schwartz y Derains indican:

En algunos casos, por ejemplo, las cuestiones jurisdiccionales a ser resueltas pueden estar tan entrelazadas con cuestiones de hecho o de derecho que no pueden decidirse adecuadamente de antemano (2005, p. 105) [traducción libre].

40 De acuerdo con Scherer et. al:

Por otro lado, cuando los asuntos de jurisdicción/ autoridad y méritos están estrechamente relacionados y ambos giran en torno a los mismos elementos de hecho, puede ser más apropiado y eficiente para decidir la objeción junto con los méritos del caso. Esto permitiría a las partes informar plenamente al Tribunal sobre las cuestiones relevantes de jurisdicción/autoridad sin correr el riesgo de que el Tribunal prejuzgue las cuestiones sustantivas (2015, p. 87) [traducción libre].

41 En el laudo parcial del Caso CCI No. 4402 se indica:

El tema de la jurisdicción sobre una parte de un Arbitraje es un clásico escenario para un laudo parcial. Puede ser claramente separado de otras materias en el caso y fácilmente de ser dispuesto por el Tribunal sin tener que ir a los méritos del caso. Está claro que una decisión sobre la cuestión de jurisdicción es de ayuda para todas las partes envueltas en el arbitraje. Finalmente, es obvio que las ventajas económicas pueden llamar tempranamente a una decisión sobre la cuestión sobre quién es la parte apropiada en el caso (1983, párr. 4) [traducción libre].

42 Como Schwartz y Derains indican:

Desde la perspectiva de las partes, una temprana decisión sobre la jurisdicción tiene la ventaja de evadir un posible gasto inútil de tiempo en los méritos mientras que haya una posibilidad que los árbitros vayan a encontrarse con que ellos no tienen jurisdicción (2005, p. 104) [traducción libre]. 


\section{REFERENCIAS}

Bärtsch, P., \& Petti, A. (2013). The Arbitration Agreement. En E. Geisinger, N. Voser, \& A. Petti (Eds.), International Arbitration In Switzerland: A Handbook for Practitioners (2da ed., pp. 25-50)

Blessing, M. (1994). Extension of the Arbitration Clause to Non-Signatories. En M. Blessing (Ed.), The Arbitration Agreement: its Multifold Critical Aspects (pp. 151-162).

Born, G. B. (2014). International Commercial Arbitration (2da ed., Vol. I). Wolters Kluwer.

Bullard González, A. (2012). ¿Y quienes están invitados a la fiesta? La incorporación de partes no signatarias al arbitraje y el artículo 14 de la Ley de Arbitraje Peruana. En Anuario Latinoamericano de Arbitraje, (2), 21-44.

(2020). Partes no signatarias: Visiones desde el proceso civil y el arbitraje [Webinar]. Capítulo Peruano del Club Español de Arbitraje. https:// bit.ly/3icr7nM

Cantuarias, F. (2014). El levantamiento del velo societario en el Perú: comentarios al caso TSG. Lima Arbitration, (6), 173-184.

Conejero, C. (2009). Multi-party Arbitration and Rule-making: Same Issues, Contrasting Approaches. En J. van den Berg (Ed.), 50 Years of the New York Convention. Wolters Kluwer.

Conejero, C., \& Irra R. (2013). La extensión del acuerdo arbitral a partes no signatarias en la ley de arbitraje peruana: algunas lecciones del derecho comparado. Lima Arbitration, (5), 56-91.

Hanotiau, B. (2006). Complex arbitrations, Multiparty, Multicontract, Multi-issues and Class Actions. Kluwer Law International.

(2011). Consent to Arbitration: Do We Share a Common Vision? Arbitration International, 27 (4), 539-554. https://doi.org/10.1093/arbitration/27.4.539.

Osterling Parodi, F. (2007). Las Obligaciones. Grijley.

Park, W. (2009). Non-Signatories and International Contracts: An Arbitrator's Dilemma. En B. Macmahon (Ed.), Multiple Party Actions in International Arbitration (pp. 1-31). Oxford University Press; Wolters Kluwer.

Ramírez, J. (2016). La vinculación de sujetos no signatarios a los efectos del pacto arbitral. Universidad Externado de Colombia.
Scherer, M., Richman, L., \& Gerbay, R. (2015). Arbitrating under the 2014 LCIA Rules: A User's Guide. Kluwer Law International.

Schwartz, E., \& Derains, Y. (2005). Guide to the ICC Rules of Arbitration (2da ed.). Kluwer Law International.

Sesin-Tabaerlli, A. (2017). Extension of the Arbitration Agreement to Non-Signatories. ICC Dispute Resolution Bulletin, (4), 17-24.

Silva Romero, E. (2011). El artículo 14 de la nueva Ley Peruana de Arbitraje: Reflexiones sobre el contrato de arbitraje - realidad. Lima Arbitration, (4), 53-69.

Silva Romero, E., \& Velarde Saffer, L. M. (2018). The extension of the arbitral agreement to non-signatories in Europe: A uniform approach? American University Business Law Review, 5(3), 371-385. https://digitalcommons.wcl.american.edu/cgi/viewcontent. cgi ?article $=1098 \&$ context $=$ aublr.

Talero Rueda, S. (2011). Extensión del pacto arbitral a no signatarios: Perspectivas en la nueva Ley Peruana de Arbitraje. Lima Arbitration, (4), 71-100.

Voser, N. (2009). Multi-party Disputes and Joinder of Third Parties. En J. van den Berg (Ed.), 50 Years of the New York Convention. Wolters Kluwer.

\section{LEGISLACIÓN, JURISPRUDENCIA Y OTROS DOCU- MENTOS LEGALES}

Bahamian company, Luxembourg company c. dos compañías francesas, Caso No. 5103 de 1988, Laudo final, ICC Int'I Ct. Arb. Bull. Vol. 2/No. 2361

Caso No. 10510 de 2000, Laudo parcial no publicado (ICC Int'I Ct. Arb.), en Hanotiau, B., Complex arbitrations, Multiparty, Multicontract, Multi-Issues and Class Actions. Kluwer Law International.

Caso No. 10758 de 2000, Laudo final, ICC Int'I Ct. Arb. Bull. Vol. 16/No. 287

Caso No. 10818 de 2001, Laudo parcial, ICC Int'I Ct. Arb. Bull. Vol. 16/No. 294

Caso No. 11160 de 2002, Laudo final, ICC Int'I Ct. Arb. Bull. Vol. 16/No. 299.

Caso No. 11405 de 2001, (ICC Int'| Ct. Arb.), en Hanotiau, B., Complex arbitrations, Multiparty, Multicontract, Multi-Issues and Class Actions. Kluwer Law International. 
Caso No. 14208/14236 de 1998, Laudo parcial, ICC Int'l Ct. Arb. Bull. Vol. 24/No. 262.

Caso No. 15116 de 2008, Laudo interino, 39 Y. B. Com. Arb. 159 (ICC Int'I Ct. Arb.).

Caso No. 15372 de 2009, Laudo parcial no publicado (ICC Int'I Ct. Arb.), en Arbitration Intelligence Materials.

Caso No. 4402 de 1983, Laudo parcial, 9 Y.B. Com. Arb. 138 (ICC Int'l Ct. Arb.).

Caso No. 5920 de 1989, Laudo interino, ICC Int'I Ct. Arb. Bull. Vol 2/No. 227.

Caso No. 6519 de 1991, Laudo final, ICC Int'I Ct. Arb. Bull. Vol. 2/No. 234.

Caso No. 9873 de 2000, Laudo interino, ICC Int'I Ct. Arb. Bull. Vol. 16/No. 285.

Código Civil [CC], Diario Oficial El Peruano, 25 de julio de 1984 (Perú).

Cour de cassation [Cas.] [Corte Suprema para asuntos judiciales], 7 Ene. 1992, Caso No. 8918708 89-18726 (Fr.).

Decreto Legislativo 1071, Decreto Legislativo que norma el arbitraje en Perú, Diario Oficial El Peruano, 1 de septiembre de 2008.
Dow Chemical France i.a. c. Isover Saint Gobain, Caso No. 4131 de 1982, Laudo interino, 9 Y.B. Com. Arb. 131 (ICC Int'I Ct. Arb.).

Empresa Minera Los Quenuales c. Vena Resources Inc, Vena Perú S.A. \& Azulcochamining S.A.C., Caso No. 2100-2011-CCL (Cámara de Comercio de Lima 2014).

Himpurna California Energy Ltd. c. PT (Persero) Perusahaan Listruik Negara, Laudo final de 4 May. 1999, 20 Y.B. Com. Arb. 13 (Ad hoc CNUDMI 2000).

Primera Sala Civil con Subespecialidad Comercial de Lima, Resolución 29 recaída en el Expediente 451-2009, 5 de marzo de 2013 (Perú).

Segunda Sala Civil del Poder Judicial, Resolución 28, 4 de octubre de 2015 (Perú).

Segunda Sala Civil con Subespecialidad Comercial de Lima, Resolución 11 recaída en el Expediente 076-2013, 20 de noviembre de 2013 (Perú).

Tribunal fédéral [TF] [Tribunal Federal], 18 Oct. 2003, 4.P.115/2003 (Suiz.). http://www.swissarbitrationdecisions.com/extension-arbitration-clause-non-signatory. 


\section{APÉNDICE \\ RESUMEN DE LA JURISPRUDENCIA ARBITRAL REVISADA}

\section{CASO CCI No. 4131 (1982)}

Esta controversia surgió a raíz de dos contratos para la distribución de equipos de aislamiento térmico en Francia. El primero de ellos se celebró en 1965 y sus partes originales fueron Dow Chemical (Venezuela) y la empresa francesa Boussois-Isolation. Posteriormente, Dow Chemical (Venezuela) cedió su posición contractual a Dow Chemical A.G -quien a su vez era subsidiaria de Dow Chemical Company-, mientras que Boussois-Isolation cedió su posición a la empresa Isover Saint Gobain.
El segundo acuerdo se celebró 1968 entre Dow Chemical Europa, también subsidiaria de Dow Chemical Company, y tres empresas francesas, las cuales posteriormente cedieron su posición a la empresa Isover Sain Gobain.

Tanto el acuerdo de 1965 como el segundo en 1968 señalaban que la entrega de los equipos de aislamiento térmico podía ser realizada tanto por Dow Chemical France como por cualquier otra subsidiaria de Dow Chemical Company. En los hechos, los equipos materia de ambos contratos fueron entregados por Dow Chemical France.

En esa línea, las dos relaciones contractuales pueden ser graficadas como se observa a continuación:

Figura 1

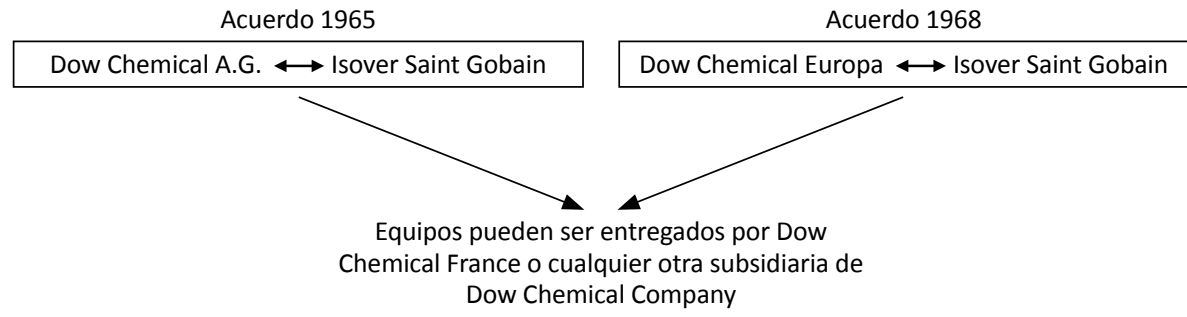

Fuente: Elaboración propia

Surgido un conflicto en relación con los contratos de 1965 y 1968, Dow Chemical A.G, Dow Chemical Company, Dow Chemical Europa y Dow Chemical France iniciaron un proceso arbitral ante la $\mathrm{CCl}$ contra Isover Sain Gobain, a quien denominaremos la demandada. En este arbitraje, la parte demandada cuestionó la jurisdicción del tribunal arbitral respecto a la Dow Chemical Company y Dow Chemical France, dado que estas no firmaron el contrato de 1965 ni tampoco el de 1968.

A fin de determinar los alcances y efectos del convenio arbitral, el tribunal arbitral analizó en el caso la mutua intención de las partes sobre la base de los hechos que dieron pie a la negociación, ejecución y culminación de los contratos, así como los posibles efectos que tendría, en este contexto, el hecho de que las demandantes pertenezcan a un mismo grupo de empresas ${ }^{43}$.
En primer lugar, con respecto a la etapa de negociación tanto del acuerdo de 1965 como del de 1968, el tribunal arbitral tuvo en consideración que Dow Chemical France fue el centro de la organización de la relación contractual con las empresas que precedieron en ambos acuerdos a la demandada. En concreto, para el tribunal arbitral, este análisis revelaba que ni los vendedores (ahora demandantes) ni los distribuidos (empresas que precedieron a la ahora demandada) le asignaron importancia a qué empresa del Grupo Dow firmaría los respectivos acuerdos. En realidad, todas las empresas del Grupo Dow vinculadas a la distribución de los equipos en Francia entendían que estaban contratando con el distribuidor o distribuidores de los equipos en dicho país y viceversa.

En segundo lugar, con respecto a la etapa de ejecución de los contratos de 1965 y 1968, el tribunal

43 Se indicó al respecto:

Considerando que el tribunal determinará, según corresponda, el alcance y los efectos de las cláusulas arbitrales en cuestión y, por consiguiente, adoptará su decisión en lo que respecta a la jurisdicción, teniendo en cuenta la común intención de las partes en este procedimiento, tal como se desprende de las circunstancias que rodean la celebración y caracterizan la ejecución y, posteriormente, la terminación de los contratos en los que aparecen. Al hacerlo, el tribunal, siguiendo, en particular, la jurisprudencia francesa relacionada con el arbitraje internacional, debe tener en cuenta también los usos conformes a las necesidades del comercio internacional, en particular, en presencia de un grupo de empresas (1982, párr. 134) [traducción libre]. 
arbitral resaltó que si bien dichos acuerdos fueron firmados por Dow Chemical A.G y Dow Chemical Europa, respectivamente, en los hechos, quien realizó la entrega de los productos contratados fue Dow Chemical France. Asimismo, resaltó que para poder cumplir con sus actividades contractuales, esta y los distribuidores debían hacer uso, necesariamente, de las marcas registradas a nombre de la Dow Chemical Company. Este hecho, sumado a que la Dow Chemical Company tenía control absoluto de las restantes demandantes, llevó al tribunal arbitral a concluir que la Dow Chemical Company tuvo una participación activa en la ejecución de los contratos.

Finalmente, con respecto a la etapa de terminación de los contratos, el tribunal arbitral tuvo en consideración los hechos antes descritos para llegar a la conclusión que Dow Chemical Company y Dow Chemical France tuvieron también una participación en la terminación de los contratos.

Así, el tribunal arbitral decidió extender el convenio arbitral tanto a Dow Chemical Company como a Dow Chemical France sobre la base de su rol en la celebración, ejecución y terminación de los contratos, del cual se desprendería la intención de todas las partes involucradas de que las no signatarias sean verdaderas partes ${ }^{44}$. A esta consideración, el tribunal arbitral le sumó el hecho de que las demandantes pertenecían a un mismo grupo de empresas, el cual constituía una sola realidad económica ${ }^{45}$.

\section{CASO CCI No. 5920 (1989)}

Este caso surge a raíz de un contrato para la construcción de una planta celebrado entre la empresa $X$ (contratista) y la empresa AZ (propietario). El contrato en cuestión fue firmado por un representante de la empresa $X$, uno de la empresa AZ y finalmente, uno de la empresa BZ (parte del mismo grupo que AZ), pese a que el contrato señalaba que la única parte contractual por parte del grupo Z era AZ.

Surgida una controversia entre las partes, la empresa $\mathrm{X}$ inició un arbitraje en contra de $\mathrm{AZ}$ y $\mathrm{BZ}$. La empresa $X$ solicitaba la incorporación de $B Z$ bajo dos argumentos en concreto: (i) que, si bien el contrato solo indicaba que la parte contractual era $A Z$, también $B Z$ (parte del mismo grupo que $A Z$ ) había firmado el contrato; $y$, (ii) que, en la ejecución de los trabajos, el personal de AZ era transferido constantemente a BZ y viceversa, de forma que no era posible diferenciarlos.

Al analizar el pedido de incorporación, el tribunal arbitral consideró que, a diferencia de la jurisprudencia arbitral pública hasta la fecha (principalmente el caso Dow Chemical), en este caso se pedía la incorporación de no signatarias como demandadas y no como demandantes ${ }^{46}$. También consideró que de acuerdo con la ley del país de su constitución, BZ no podía celebrar contratos con empresas extranjeras, como era la empresa $X$, razón por la cual la parte contractual era AZ.

44 Se indicó que

considerando, en particular, que la cláusula compromisoria expresamente aceptada por algunas de las sociedades del grupo debe obligar a las demás sociedades que, en virtud de su papel en la celebración, ejecución o terminación de los contratos que contienen dichas cláusulas, y de acuerdo con la común intención de todas las partes en el procedimiento, parezcan haber sido verdaderas partes en dichos contratos o haberse visto principalmente involucradas en ellos y en los litigios a que puedan dar lugar (1982, párr. 135) [traducción libre].

45 Se concluyó:

Considerando que, independientemente de la identidad jurídica distinta de cada uno de sus miembros, un grupo de empresas constituye una misma realidad económica (une réalité économique unique) que el Tribunal Arbitral debe tener en cuenta cuando se pronuncie sobre su propia competencia, a reserva de lo dispuesto en el artículo 13 (versión de 1955) o en el artículo 8 (versión de 1975) del Reglamento de la CCI. (...) Considerando que los tribunales arbitrales de la $\mathrm{CCl}$ ya se han pronunciado en este sentido (véanse los laudos en el caso No. 2375 de 1975, Journal du droit international 1976.973; y en el caso No. 1434 de 1975, id. en 978). Las decisiones de estos tribunales crean progresivamente una jurisprudencia que debe tomarse en cuenta, dado que saca conclusiones de la realidad económica y se ajusta a las necesidades del comercio internacional, a las que deben responder las normas específicas del arbitraje internacional, elaboradas sucesivamente por ellos mismos (1982, párr. 135) [traducción libre].

46 Se indicó:

Aunque en el presente caso el concepto de "grupo de sociedades" sería particularmente apropiado en vista de la finalidad misma del acuerdo y de la actitud de todas las partes que participan en su aplicación y cumplimiento, el Tribunal Arbitral no tiene ninguna base en el Concordato o en la Convención de Nueva York para introducir el concepto, como cuestión de derecho, ni tampoco lo tienen los laudos y el caso inglés: El presente caso no es un caso en el que varios demandantes quisieran acogerse a una cláusula de arbitraje firmada por uno de ellos, sino un caso en el que un demandante busca unirse a varios demandados. No se trata de un caso en el que uno de los múltiples demandados fuera la sociedad matriz del otro y firmara una cláusula de arbitraje "para sus filiales" así como para sí mismo. Como se explicará en el resto del presente laudo, aunque la firma de RZB aparece en la página de firmas, RZA era la única empresa de RZ que era parte en el acuerdo de arbitraje porque RZB carecía de la capacidad para celebrar dicho acuerdo en primer lugar (1991) [traducción libre]. 
Fue sobre la base de dichas consideraciones que el tribunal arbitral decidió, finalmente, rechazar el pedido de incorporación de parte no signataria, declarando que no tenía jurisdicción sobre BZ.

\section{CASO CCI No. 6519 (1991)}

Esta controversia surgió a raíz de un acuerdo celebrado entre el señor Paul y la empresa Z con la finalidad de crear un grupo de hoteles. Este grupo de hoteles sería controlado a través de una empresa holding (empresa A) la que, a su vez, sería propiedad del señor Paul y de la empresa Z. En este sentido, tanto el señor Paul como la empresa $Z$ se obligaron a transferir a favor de la empresa $A$ acciones sobre otras empresas, de modo que esta pueda volverse la holding del nuevo grupo hotelero a crearse.

Surgida una controversia entre las partes, el señor Paul y las empresas A, B y C (siendo ellas controladas por el señor Paul) iniciaron un arbitraje en contra de la empresa $\mathrm{Z}$ ante la $\mathrm{CCl}$.

Al analizar el pedido de incorporación de partes no signatarias, el tribunal arbitral consideró que el hecho consistente en que la empresa $A$, la empresa $B$ y la empresa $C$ fueran parte del mismo grupo (el grupo Paul), no era suficiente para poder extender el convenio a las no signatarias. Más bien indicó que se necesitaba analizar la participación activa de las partes en la negociación del contrato o si estas estuvieron directamente implicadas en el mismo ${ }^{47}$.
Fue bajo estas premisas que el tribunal arbitral concluyó que no tenía jurisdicción sobre la empresa $B$ y la empresa $C$, pues ellas no tuvieron participación en la negociación del contrato y la única vinculación con su ejecución fue ser las empresas cuyas acciones el señor Paul transfirió -directa o indirectamente- a favor de la empresa $\mathrm{A}^{48}$.

En relación con esta última, el tribunal arbitral consideró que los efectos del convenio arbitral sí le alcanzaban, en tanto que la empresa A era una beneficiaria del contrato celebrado entre el señor Paul y la empresa $Z$ (teoría que escapa a los fines del presente artículo).

\section{CASO CCI No. 9873 (2000)}

Por su parte, esta controversia surgió en relación con un contrato celebrado entre la empresa A, la empresa $Y$ el señor $X$ para la gestión de un contrato de concesión. Producida una controversia, la empresa $A$, junto con las empresas $B$ y $C$ y el señor $D$ iniciaron un arbitraje contra el señor $X$. El señor $X$ se opuso a la incorporación de las empresas B y $C$, así como del señor $D$, pues ninguno había firmado el contrato en cuestión.

Al analizar el pedido de incorporación de las partes no signatarias, el tribunal arbitral tuvo en consideración que, a su criterio, la calidad de persona natural o persona jurídica de la no signataria no tenía impacto en el análisis ${ }^{49}$. Ello siempre y cuando se lograra acreditar la existencia de un consentimiento implícito, el cual no pasaba por el hecho de

47 Se añadió:

Visto que, sin negar la realidad económica de un "grupo de empresas", el ámbito de aplicación de una cláusula de arbitraje puede ampliarse a las empresas no signatarias que tengan una importancia jurídica distinta sólo si han desempeñado un papel activo en las negociaciones que condujeron al acuerdo que contiene la cláusula, o si están directamente implicadas en el acuerdo (1991) [traducción libre].

El tribunal arbitral añadió:

Mientras que la transferencia a ADA de las 102,631 acciones pertenecientes al Sr. Paul no permite a la BDB, por las razones antes mencionadas, alegar que está implicada en el Protocolo de 1987 y, por consiguiente, obligada por la cláusula de arbitraje incluida en el Protocolo; el Sr. Paul no ha hecho más que disponer, a su discreción, de las acciones que poseía, directa o indirectamente, sin comprometer a la BDB como entidad jurídica independiente; la posición mayoritaria que posee el Sr. Paul en esa sociedad no altera en absoluto esta situación; en efecto, en el Protocolo de 1987 se indica claramente que las acciones cedidas por el Sr. Paul a la ADA son cedidas por él mismo o por las sociedades bajo su control "por las que responde" ("se porte fort"); el concepto mismo de fianza es contrario a toda idea de representación, ya que quien responde por otro sólo se compromete a sí mismo, sin comprometer a la persona cuyo acuerdo promete bajo su propia responsabilidad; en ausencia, pues, de toda representación y considerando que el Sr. Paul podría desprenderse personalmente de las acciones que poseía como accionista de la BDB, la demanda de ésta no es competencia del Tribunal Arbitral; 2) Considerando que, por idénticas razones, la misma solución debe aplicarse a la CDC (1991) [traducción libre].

49 Según el tribunal arbitral

los principios que rigen la extensión de la cláusula hacia los demandados no firmantes pueden considerarse generalmente aplicables, mutatis mutandis, a un caso en que una parte - individuo o empresa - trate de acogerse a una cláusula de arbitraje a la que no se haya adherido formalmente. En otras palabras, tanto si los Demandantes Nos. 2 a 4 tratan de hacer uso de la cláusula como si el demandado hubiera iniciado un procedimiento de arbitraje contra [el Demandante 1] y habría tratado de extender la cláusula a los Demandantes Nos. 2 a 4, la respuesta a la cuestión debería ser la misma. Los principios que se aplican en el primer caso también rigen la respuesta al segundo y viceversa (2005, párr. 51) [traducción libre]. 
pertenecer a un mismo grupo ${ }^{50}$, sino por su participación, ya sea en la negociación o en la ejecución del contrato ${ }^{51}$.

Así, el tribunal arbitral concluyó que no tenía jurisdicción respecto de la empresa $B$ y la empresa $C$, en tanto la única vinculación de dichas empresas con el contrato fue que, durante los años que este fue ejecutado, la empresa B era dueña de la empresa $A$ y que, a su vez, la empresa $C$ era dueña de la empresa B. De ese modo, para el tribunal arbitral, esta relación económica -no conocida por el señor X- no justificaba incorporar a dichas empresas al arbitraje.

Respecto al señor $D$, el cual era en última instancia quien controlaba a la empresa $\mathrm{C}$, si bien el tribunal arbitral reconoció que tuvo cierta participación en las negociaciones con el señor $X$ que llevaron a la firma del contrato, concluyó, sin embargo, que no se podía determinar que existía un acuerdo implícito entre las partes para que este forme parte del contrato y del convenio arbitral. Esto debido a que el señor $D$, en un balance de sus intereses, decidió que fuese la empresa A quien firmase el contrato. Dicha decisión comportaría, además, el no tener un rol activo en las actividades de dicha empresa, ejerciendo meramente un rol de supervisión ${ }^{52} 48$.

\section{CASO CCI No. 10510 (2000)}

Esta controversia surgió a raíz de un contrato celebrado entre la empresa S y la empresa B Francia en virtud del cual la empresa S distribuiría en Japón los productos de lujo que serían suministrados por la empresa B Francia.
Resuelto el contrato por supuestos incumplimientos, la empresa B Francia y su subsidiaria B Japón iniciaron un arbitraje en contra de la empresa $S$, reclamando el pago de daños y perjuicios. La empresa $\mathrm{S}$ se opuso a la incorporación de $\mathrm{B}$ Japón señalando que esta empresa no había firmado el contrato de distribución.

Al analizar la oposición presentada por la empresa $S$, el tribunal arbitral consideró el rol activo que había tenido B Japón en la negociación, ejecución y terminación del contrato de distribución, tomando en consideración diversos aspectos:

(i) El señor Z, director de B Japón, se presentó también durante las negociaciones como representante de B Francia y envió cartas a la empresa $\mathrm{S}$ con el membrete de B Japón y el de B Francia.

(ii) El señor $X$, presidente de la empresa B Francia, envió cartas a la empresa $\mathrm{S}$ con el membrete de $B$ Japón.

(iii) Fue el señor $Z$ quien realizó el acercamiento de la empresa B Francia y B Japón con la empresa S. Asimismo, fue quien redactó la primera versión del contrato de distribución que contenía el convenio arbitral y tuvo un papel decisivo en la celebración del mismo.

(iv) Durante la ejecución del contrato, el contacto con la empresa B Francia se canalizó a través de $B$ Japón.

(v) Finalmente, la decisión de terminar el contrato se tomó en las oficinas de B Japón, estan-

50 Se indicó:

Por otra parte, se acepta de forma unánime que el hecho de que los firmantes del acuerdo de arbitraje y los no firmantes pertenezcan al mismo grupo o la dominación de un accionista nunca son en sí mismos suficientes para justificar una extensión de la cláusula (2005, párr. 46) [traducción libre].

51 Se añadió:

Para permitir la extensión de la cláusula a los no firmantes, los árbitros y los tribunales nacionales se requiere siempre la prueba de la existencia de la intención -al menos implícita- de todas las partes, de que los no firmantes sean partes en el contrato subyacente y en su cláusula de arbitraje. Aunque esto es evidente, cabe destacar que la intención de que los no firmantes sean parte en el acuerdo debe ser común a estos últimos y a la(s) otra(s) parte(s) en la cláusula de arbitraje. La existencia de esa intención -en la medida en que sólo está implícita- se encuentra en el papel que los no firmantes han desempeñado en la celebración y el cumplimiento del acuerdo. Como señalaron los árbitros en el histórico caso Isover SaintGobain c. Dow Chemicals (2005, párr. 42-43) [traducción libre].

52 El tribunal indicó:

Sin embargo, a la luz de la jurisprudencia reiterada en los párrafos 43 a 47 , no encontramos que los hechos del caso hayan permitido inferir una intención implícita tanto de la Demandada como de la Demandante $\mathrm{N}^{\circ} 4$ de que esta última tenga derechos y obligaciones en relación con el Acuerdo de Gestión o, en particular, en relación con la cláusula de arbitraje contenida en él. La Demandante $N^{\circ} 4$ podría haber elegido ser y sin duda habría sido aceptada como parte en el Acuerdo de Gestión junto con o en lugar de [la Demandante № 1]. En cambio, optó por ejercer esta actividad únicamente a través de [la Demandante 1], elección que sin duda fue el resultado de una ponderación de sus propios intereses. También podría haber optado por desempeñar un papel muy activo en las actividades de gestión (limitadas) de [Demandante 1] relacionadas con el [complejo de edificios] y tener a [Demandante 1] como una sociedad de cartera puramente formal de esas actividades. Eligió asumir un papel distante y meramente supervisor, y no se le puede permitir ahora que afirme lo contrario, sólo porque pueda ser de su interés hacerlo (2005, párr. 50$)$ [traducción libre]. 
do esta empresa estrechamente vinculada a

la decisión y también a sus consecuencias.

Sobre la base de lo anterior, el tribunal arbitral consideró que B Japón tuvo un rol activo en la negociación, ejecución y terminación del contrato de distribución, por lo que aceptó incorporarla al arbitraje.

\section{CASO CCI No. $10758(2000)$}

Por su parte, esta controversia surgió en relación a un contrato para el diseño, suministro y construcción de una planta industrial celebrado entre la empresa A y la empresa B.

Surgida una controversia entre las partes del contrato, la empresa matriz de A (demandante) decidió iniciar un arbitraje ante la $\mathrm{CCl}$ contra la empresa $B$ y la empresa matriz de B, la cual controlaba el $100 \%$ de las acciones de dicha empresa.

Los hechos de la controversia fueron los siguientes:

(i) En 1986 se firmó el contrato original para la ejecución de la planta industrial entre $C$, una organización del sector público del Estado X, y una empresa italiana. Este contrato nunca surtió efectos.

(ii) En 1988 se reanudó el proceso de oferta, solo que esta vez fue liderado por $D$, otra organización del sector público del Estado $\mathrm{X}$, a quien por mandato legal se le habían asignado las responsabilidades de $C$. Las ofertas se presentaron en las oficinas de $D$, al igual que las reuniones respecto a los detalles del contrato. También fue la empresa $D$ quien informó a la empresa A que había ganado la oferta y quien, en general, controló la etapa final del proceso de negociación. Sin embargo, el contrato terminó siendo firmado por la empresa B y no por la empresa D. (iii) En algún momento no especificado en el laudo (estimamos que posteriormente a la firma del contrato), todos los derechos y obligaciones de $D$ fueron transferidos por mandato legal a la empresa matriz de B la que, a su vez, era controlada en un $100 \%$ por el Estado X.

Antes de entrar a comentar el análisis que realizó el tribunal arbitral en este caso, debemos hacer algunas precisiones. Primero, el laudo en este caso no explica la razón por la cual es la matriz de A y no la empresa A quien demanda en el arbitraje. Segundo, el tribunal arbitral analiza tanto la teoría del levantamiento del velo societario como el comportamiento de las partes involucradas en la negociación, ejecución y terminación del contrato. Para fines del presente artículo solo nos referiremos al segundo análisis. Tercero, pese a que el tribunal arbitral reconoce expresamente en el laudo que la jurisprudencia arbitral permite incorporar partes no signatarias cuando, de una participación activa en el iter contractual, se pueda desprender un consentimiento implícito para arbitrar ${ }^{53}$, el análisis que realiza del comportamiento de las partes no es para encontrar un consentimiento implícito, sino un convenio arbitral por escrito. Este último hecho debe considerarse al evaluar las conclusiones del tribunal arbitral. Habiendo realizado estas precisiones, veremos ahora cuál fue el análisis del tribunal arbitral.

En primer lugar, en lo que corresponde a la etapa de negociación, se le otorgó importancia a que el contrato fuese solo firmado por la empresa B. Ello pese a que $D$, quien posteriormente transferiría todos sus derechos y obligaciones a la empresa matriz de $B$, estuvo sumamente involucrada en las negociaciones, pues este hecho señalaría la intención de $\mathrm{D}$ de respetar la personalidad jurídica independiente de la empresa B. Por lo tanto, no se desprendería de la participación el consentimiento de $D$ para ser parte del contrato o del arbitraje ${ }^{54}$.

53 En el laudo se indicó que

los conceptos de "grupo de empresas" o "realidad económica única" han aparecido en muchos laudos y se han discutido en artículos académicos, pero su utilidad analítica podría ser cuestionada. Estos conceptos fomentan la evidencia y la argumentación, como en este caso, sobre lo que define a un grupo de empresas o a una única realidad económica. La extensión de un acuerdo de arbitraje a un no firmante no es una mera cuestión de estructura o control empresarial, sino más bien una cuestión de participación del no firmante en la negociación, ejecución o cumplimiento del contrato, o de su conducta (incluidas las representaciones expresas o implícitas o la mala fe), hacia la parte que solicita la inclusión (o exclusión) del no firmante en el arbitraje. Es de esta participación en el contrato o conducta hacia la otra parte que el Tribunal Arbitral puede inferir ". . . la intención mutua de todas las partes ... ." que ha sido reconocida en muchos laudos (incluido el caso Dow Chemical) como justificante de la extensión del acuerdo de arbitraje a un no firmante (2005, párr. 17) [traducción libre].

54 En concreto, se indicó

De los documentos proporcionados se desprende que [D] se involucró en la negociación del Contrato: se presentaron ofertas en las oficinas de [D], se celebraron reuniones sobre los detalles del contrato con los representantes de [D] y [D] informó al Demandante del éxito de su oferta. Esta correspondencia indica que [D] colaboró con, incluso 
Por su parte, al analizar la etapa de ejecución contractual, el tribunal arbitral tuvo en consideración la naturaleza del contrato, el cual requería un alto nivel de coordinación y comunicación entre las partes. Por lo anterior, para el tribunal arbitral fue sumamente resaltante el hecho de que no se hubiese presentado una sola prueba que acreditase la participación de la empresa matriz de B durante los 8 años de vigencia del contrato (entre 1988 y 1996) ${ }^{55}$.

Para el tribunal arbitral, las pruebas presentadas por la demandante que acreditaban la participación de la empresa matriz de $B$ se habían realizado tras el inicio de la controversia ( 8 años después de la firma del contrato) en apoyo a la Empresa B y, por lo tanto, no calificaban como una muestra de consentimiento para ser parte del contrato o del arbitraje. Para el tribunal arbitral de este caso es perfectamente válido que una empresa matriz asista a su subsidiaria para resolver disputas vinculadas a proyectos de gran envergadura en las cuales estas se encuentren involucradas, sin que necesariamente esté dando su consentimiento para ser parte del contrato o del arbitraje ${ }^{56}$.

\section{CASO CCI No. 10818 (2001)}

Esta controversia surgió en relación con un contrato de distribución exclusiva celebrado entre la em- presa A y la empresa B. Un año después de la firma del contrato, la empresa A le informa a la empresa B que la empresa C (la cual era parte del mismo grupo societario que la empresa A) le prestaría asistencia técnica, operacional y de marketing. A partir de esta fecha, la relación de la empresa $A$ se dio de forma exclusiva con la empresa $\mathrm{C}$, quien también vendió los productos materia del contrato. Poco antes de su terminación, la empresa $\mathrm{C}$ le alcanzó a la empresa $B$ un borrador de un nuevo acuerdo, quien encontró inaceptables los términos allí contenidos.

Después de ello, la empresa A resolvió el contrato alegando que sus ventas se habían visto perjudicadas por competidores en el mercado materia del contrato y que la empresa $C$ había estado alejando a sus clientes. La empresa $\mathrm{C}$ objetó su incorporación al arbitraje, señalando que nunca había firmado acuerdo alguno con la empresa $A$.

Después de criticar la así llamada doctrina del grupo de sociedades ${ }^{57}$, el tribunal arbitral del caso concluyó que si bien la jurisprudencia del Tribunal Federal Suizo (siendo la ley suiza aplicable a este caso) había reconocido la posibilidad de incorporar al arbitraje, en aplicación del principio de buena fe, a partes no signatarias que en virtud de su conducta hubiesen consentido arbitrar; las

quizás controló, las etapas finales de las negociaciones del Contrato. Sin embargo, en ningún momento de las comunicaciones en las que se basó la Demandante se sugiere que [D] aceptara su cláusula de arbitraje. Además, y lo más importante, el propio Contrato firmado poco después de estas comunicaciones pre-contractuales fue firmado con $[B]$ solamente. Como el Demandado argumentó en su presentación final, el Demandante firmó este contrato con [B] sin reservas. Si el Demandante hubiera tenido la intención de que [D] fuera parte en el Contrato o en su cláusula de arbitraje, podría haber insistido en ese momento (2009, párr. 25) [traducción libre].

55 Al respecto, se señaló:

Esta relación es muy diferente de los casos de suministro de bienes en los que la identidad de la empresa concreta de un grupo que realmente suministra el producto puede ser de poca importancia para el comprador o el vendedor. Por el contrario, se requiere un alto grado de cooperación y comunicación entre las partes para cumplir el contrato. Sin embargo, la Demandante no presentó ninguna prueba entre la firma del contrato en diciembre de 1988 y septiembre de 1996 de la participación del demandado en el cumplimiento o la aplicación del contrato. No podría haber, en nuestra opinión, una indicación más clara de que [la Demandada] no era parte del Contrato (2009, párr. 26) [traducción libre].

56 Al respecto, se indicó:

El demandante presentó más pruebas de que [el demandado] se involucró en el contrato una vez que surgió la controversia. El Tribunal considera que esta participación, que comenzó ocho años después de la firma del Contrato, no revela ninguna intención de aceptar ninguna responsabilidad por el contrato o su cláusula de arbitraje. La sociedad matriz puede ayudar a una filial de su entera propiedad a resolver una controversia relativa a un proyecto importante en el que esta última participe, especialmente cuando la ley le obliga a supervisar a sus filiales como en el presente caso, sin por ello hacerse cargo del proyecto; de lo contrario, podría asumir retrospectivamente las responsabilidades que no contrató en el Úrst lugar o convertirse ella misma en parte en la controversia o en el consiguiente arbitraje (2009, párr. 27) [traducción libre].

57 En concreto, se detalló:

La decisión de Dow Chemical se basa en la doctrina denominada "grupo de sociedades", según la cual un acuerdo de arbitraje celebrado por un miembro de un grupo se extiende a otros miembros. Este enfoque ha sido ampliamente criticado. No tiene en cuenta los principios básicos del derecho reconocido en el derecho Suizo y, al parecer, en el derecho Portugués, como el principio de santidad de los contrato y la regla básica de que los acuerdos arbitrales (que representan una renuncia de los tribunales estatales) no deben interpretarse de manera demasiado amplia. También contradice la noción de la entidad separada de cada persona jurídica. Es una piedra angular del derecho empresarial y la práctica de una empresa que se ocupa exclusivamente de sí misma mediante la firma también obliga, pero se excluye a sí misma de los demás, incluso si esos otros son empresas afiliadas a ella dentro de un mismo grupo. Por estas razones, la doctrina del grupo societario debe ser rechazada (2005) [traducción libre]. 
normas consideradas por el Tribunal Federal Suizo en dicho caso (Convención de Nueva York) no eran aplicables al arbitraje. Era aplicable la Ley de Arbitraje Suiza, la cual requería que el consentimiento necesariamente se dé por escrito.

Fue por esta razón que el tribunal arbitral consideró que la participación activa de la empresa $C$ en la ejecución del contrato no era suficiente para entender que esta había renunciado a su derecho a que las controversias que se le vinculen sean conocidas en las cortes nacionales.

\section{CASO CCI No. 11160 (2002)}

Esta controversia surgió de un contrato celebrado entre una subsidiaria venezolana de una empresa de ingeniería latinoamericana (empresa A) y la subsidiaria venezolana de una empresa de ingeniería europea (empresa B) en relación a trabajos vinculados al desarrollo de un proyecto que fue adjudicado a un consorcio de empresas internacionales dentro del cual se encontraba la matriz de la empresa $B$ (empresa $M B$ ). Después de un infructuoso intento de llegar a un acuerdo, la empresa $\mathrm{A}$ inició un arbitraje ante la $\mathrm{CCl}$ en contra de la empresa B y su matriz, la empresa MB. Las demandas objetaron la jurisdicción del tribunal arbitral respecto de la empresa $\mathrm{MB}$, en tanto que esta no había firmado el contrato que contenía el convenio arbitral.

Al resolver la objeción jurisdiccional, el tribunal arbitral reconoció que el consentimiento para arbitrar se puede manifestar de forma implícita, si es que la parte no signataria ha tenido un rol determinante en la celebración y ejecución del contrato ${ }^{58}$, por lo que procedería a analizar la participación que ha tenido la empresa MB en dichas etapas del iter contractual, encontrando:

(i) Que durante el transcurso de tiempo entre la licitación (1993) y la firma del contrato (1998), todas las relaciones legales de la empresa $\mathrm{A}$ respecto del proyecto habían sido mantenidas con la empresa MB; (ii) Que la empresa A había mantenido las negociaciones del contrato con la empresa MB;

(iii) Que los pagos bajo el contrato, en una etapa temprana del proyecto, habían sido realizado por la empresa MB;

(iv) Que los representantes de la empresa MB y B eran los mismos para este proyecto;

(v) Que todas las reuniones relevantes no fueron llevadas en Caracas, donde se encontraban las oficinas de la empresa $B$, sino que se habían realizado en el Reino Unido, donde se encontraban los project headquarters de la empresa MB; $y$,

(vi) Que la única razón por la cual la empresa B entró en la relación contractual fue para que el proyecto calificase para una exoneración del IGV de acuerdo con la ley venezolana (país donde se ejecutó el proyecto materia de disputa).

Fue en base a esta participación activa en la negociación y ejecución del contrato de la empresa $M B-y$ no en el hecho de que esta era la matriz de la empresa $\mathrm{B}$ - que el tribunal arbitral concluyó que la empresa MB era "la mente, alma y parte del cuerpo del Contrato" 59 (2005), extendiéndole los efectos del convenio arbitral.

\section{CASO CCI No. 14208/14236 (1998)}

Esta controversia surgió a raíz de un contrato de construcción celebrado entre el propietario (empresa A) y el contratista (empresa B). Cinco meses después de la firma del contrato en cuestión, el grupo societario al que pertenencia la empresa $B$ fue adquirido por otra empresa (empresa matriz). Posteriormente a que la empresa $B$ dejara de ejecutar el contrato, la empresa $A$ inició un arbitraje ante la $\mathrm{CCl}$ en contra de la empresa $\mathrm{B}$ y la empresa matriz.

La empresa A fundamentó su solicitud de incorporación sobre la base de tres teorías: (i) consen-

58 En específico se indicó que

la participación activa de [un no signatario] en la negociación, preparación y conclusión del Contrato, y en algunos casos en la ejecución del mismo, determinan que la intención de las partes puede ser inferida razonablemente como la extensión del Contrato y del convenio arbitral a [los no signatarios] (2005) [traducción libre].

59 Se señaló:

Este árbitro es consciente de que el hecho de que los signatarios y no signatarios de la cláusula de arbitraje pertenezcan al mismo grupo de empresas no justifica por sí solo la extensión de la cláusula de arbitraje. En el presente caso, ese hecho por sí solo tampoco sería suficiente, pero las pruebas apoyan la conclusión de que [el demandado 2] era y sigue siendo la mente y el alma, y en parte el cuerpo, de la C... contrato del proyecto (2005) [traducción libre]. 
timiento expreso, (ii) consentimiento implícito y (iii) levantamiento del velo societario.

Si bien el tribunal arbitral terminó aceptando la teoría del levantamiento del velo societario ${ }^{60}$, para los fines del presente artículo nos centraremos en analizar los argumentos presentados por las partes y lo decidido por el tribunal arbitral con respecto a la teoría del consentimiento implícito.

El principal fundamento de la empresa A bajo la teoría del consentimiento implícito era que quien había ejecutado el contrato en los hechos era la empresa matriz, toda vez la empresa $B$ había sido reducida a un mero cascarón tras la adquisición mencionada párrafos arriba.

Por su parte, la empresa $B$ y la empresa matriz rechazaron los argumentos de la empresa $A$, señalando que fue la empresa $B$ quien continuó ejecutando el contrato tras la adquisición y que los supuestos hechos que llevarían a que la empresa A afirmase que fue la empresa matriz quien lo ejecutó serían, en realidad, una manifestación de una reorganización del grupo en buena fe, de acuerdo a la práctica estándar después de una adquisición de empresas.

Al analizar el argumento del consentimiento implícito, el tribunal arbitral tuvo en consideración, entre varios hechos, los siguientes:

(i) Que después de la adquisición, la empresa B pasó a ser parte de la división de servicios de construcción de la empresa matriz; (ii) Que todas las oficinas de la empresa B fueron cerradas o transferidas a la empresa matriz;

(iii) Que la empresa B progresivamente suspendió todas sus actividades;

(iv) Que los contratos de la empresa B fueron novados a favor de la empresa matriz, salvo el contrato materia del arbitraje, siendo este el único contrato que la empresa $\mathrm{B}$ continuaba ejecutando alrededor del mundo;

(v) Que la empresa B no tenía departamento contable, ni de recursos humanos, ni legal. Todas estas áreas eran manejadas por la empresa matriz;

(vi) Que la empresa B abandonó su marca y paso a utilizar la marca corporativa de la empresa matriz. Además, todos los proyectos de la empresa B pasaron a denominarse proyectos de la empresa matriz;

(vii) Que la gerencia del proyecto fue proporcionada exclusivamente por ejecutivos de la empresa matriz;

(viii) Que el vicepresidente ejecutivo de la empresa matriz notificó a la empresa A que el vicepresidente sénior de la empresa matriz fue asignado como corporate manager para el proyecto de construcción. En este sentido, los representantes de la empresa B respondían directamente al vicepresidente sénior de la empresa matriz;

60 En el laudo se señaló que:

Habiendo revisado y discutido cuidadosamente los hechos anteriores, el Tribunal Arbitral ha llegado a la conclusión unánime de que el comportamiento de [la empresa matriz] fue abusivo. Es evidente, según consta en el expediente, que [Empresa Matriz] controla y domina [el Contratista], en particular con respecto a su contrato con [el Empleador] En el mismo momento en que parecía que [el Contratista] podría incurrir en responsabilidad sustancial frente a [el Empleador], [la Empresa Matriz] en [país Y], quedando el contrato, sin embargo, a nombre de [el Contratista].Al hacerlo, abusó de la estructura societaria para proteger sus propios intereses a costa de los posibles acreedores de [el Contratista] es negativa, sus estados de ingresos auditados indican pérdidas netas y [la Empresa Matriz], que tiene la carga de la prueba a este respecto, no ha podido convencer al Tribunal de Arbitraje de que, a pesar de la transferencia de activos, la responsabilidad de [el Contratista] está adecuadamente cubierta por seguros. En otras palabras, [la Empresa Matriz] ha abusado de su control sobre [el Contratista] para transferirle a la sociedad la mayor parte de la responsabilidad de [el Contratista]. Es evidente, según consta en el expediente, que [la Empresa Matriz] controla y domina [el Contratista], en particular con respecto a su contrato con [el Empleador]. En el mismo momento en que parecía que [el Contratista] podría incurrir en una responsabilidad sustancial frente a [el Empleador], [la Empresa Matriz] transfirió todos los activos de [el Contratista] (excepto los relativos al [proyecto de construcción]) a una filial de [la Empresa Matriz] en [país Y], quedando el Contrato, sin embargo, a nombre de [el Contratista]. Al hacerlo, abusó de la estructura societaria para proteger sus propios intereses a costa de los posibles acreedores de [el Contratista]. La capitalización de [el Contratista] es negativa, sus estados de ingresos auditados indican pérdidas netas y [la Empresa Matriz], que tiene la carga de la prueba a este respecto, no ha podido convencer al Tribunal de Arbitraje de que, a pesar de la transferencia de activos, la responsabilidad de [el Contratista] está adecuadamente cubierta por seguros. En otras palabras, [la Empresa Matriz] ha abusado de su control sobre [el Contratista] para transferirle la mayor parte de la empresa". Por consiguiente, el Tribunal de Arbitraje considera que este es un caso apropiado para traspasar el velo y extiende a [la Empresa Matriz] sobre esta base la cláusula de arbitraje contenida en el Contrato. Por consiguiente, el Tribunal decide que tiene jurisdicción tanto sobre [el Contratista] como sobre [la Empresa Matriz], de conformidad con el artículo 6(2) del Reglamento (2013, párrs. 441-442) [traducción libre]. 
(ix) Que la orden de cambio número 2 fue firmada por el vicepresidente sénior de la empresa matriz, pese a que este no había ostentado ningún cargo en la empresa $B$ hasta meses después de la firma.

Pese a los hechos antes descritos, el tribunal arbitral concluyó que no existía un consentimiento implícito de las partes para que la empresa matriz sea considerada como parte no signataria del contrato o del arbitraje.

El tribunal arbitral llegó a tal conclusión partiendo de la premisa de que el consentimiento implícito no solo es el de la parte no signataria, sino también de las partes signatarias. Al respecto, el tribunal arbitral resaltó que, pese a todos los hechos antes narrados, la empresa $A$ en ningún momento se dirigió a la empresa matriz durante la ejecución del contrato, presentando sus comunicaciones y reclamos exclusivamente a la empresa $B$. Así, fue recién después de que el contrato se dejó de cumplir que la empresa A trajo a colación el argumento de la calidad de parte de la empresa matriz. En ese sentido, para el tribunal arbitral, no existió un consentimiento implícito por parte de la empresa A con respecto a que la empresa matriz sea parte del contrato o del convenio arbitral ${ }^{61}$.

Adicionalmente, el tribunal arbitral resaltó que, si bien era innegable que la empresa matriz participó en la ejecución del contrato, no lo hizo durante la negociación y terminación de este, razón por la cual tampoco se podía extender el convenio arbitral $^{62}$.

\section{CASO CCI No. 15116 (2008)}

Esta controversia surgió en relación con un contrato de agencia celebrado entre la empresa A (principal) y el señor $X$ (agente) a fin de que este último promueva las ventas de los productos elaborados por la empresa A en Turquía.

Durante la ejecución del contrato, el señor $X$ recibió un correo electrónico enviado por la empresa B (sobre la cual la empresa A tenía la mayoría de acciones) adjuntándole una lista de proyectos y cuotas de venta. El señor $X$ respondió dicho correo a la empresa A señalando que rechazaba los adjuntos enviados por la empresa $B$, pues no tenía conocimiento de ella. La empresa $A$ respondió señalando que el envío del correo por la empresa $B$ fue un error, adjuntó la lista de proyecto y las cuotas de venta correctas e introdujo a la empresa $\mathrm{B}$ como el "brazo" encargado de la manufactura de la empresa $A$.

Sin embargo, una disputa surgió entre las partes respecto al supuesto incumplimiento del señor $X$ de alcanzar los mínimos de venta pactados en el contrato, entre otras controversias. Ello conllevó a que el señor $\mathrm{X}$ iniciara un arbitraje en contra de la empresa $A$ y de la empresa $B$, alegando que (i) ambas pertenecían al mismo grupo de empresas y, (ii) que la empresa $B$ había participado en la ejecución del contrato. Tanto la empresa A como la empresa B objetaron la participación de esta última en el arbitraje, alegando que, sin perjuicio del correo mencionado por el señor $\mathrm{X}$, la empresa $\mathrm{B}$ había sido una empresa durmiente hasta un año después de la celebración del contrato y que, en los hechos, no había participado en su ejecución.

Al resolver la objeción jurisdiccional, el tribunal arbitral descartó la aplicación de la así denominada teoría del grupo de sociedades, cuestionando incluso la relevancia de la existencia de un grupo en el análisis de la incorporación de partes no signatarias. Para el tribunal arbitral, el factor determinante para la incorporación de una parte no signataria es la mutua intención de las partes evi-

61 En concreto, se indicó:

Por lo general, los tribunales arbitrales han extendido una cláusula de arbitraje a un no signatario cuando han podido concluir, como reconoce el Profesor [A], que la conducta del no signatario, en la celebración, el cumplimiento y, eventualmente, la terminación del acuerdo, fue una prueba clara de la intención de las partes (es decir, de ambas partes) de que el no signatario fuera parte en el contrato y en su cláusula de arbitraje. En este caso, el expediente no prueba ninguna intención de ese tipo por parte [del Empleador]. Como señaló el Profesor [C], el expediente demuestra que "[el Empleador] nunca reaccionó de ninguna manera mientras el contrato estaba ejecutando realmente. Sólo después de la iniciación del litigio, una vez que la ejecución del contrato ya se había interrumpido, [el Empleador] decidió repentinamente recurrir el argumento de la calidad de parte de [Empresa Matriz]. Sin embargo, parece que [el Empleador] se refiere a factores anteriores a las iniciativas procesales que esta empresa ya había tomado contra [el Contratista]. Si los elementos sobre los que [el Empleador] fundamenta su caso son exactos, entonces [el Empleador] debería haber reaccionado [antes] y, por lo tanto, debería haberse comportado dirigiéndose únicamente a [la Empresa Matriz] (o a [la Empresa Matriz] - [el Contratista]... (2013, párr. 442) [traducción libre].

62 Al respecto se añadió:

[Además, si [la Empresa Matriz] ha interferido sin duda alguna en el cumplimiento del Contrato, no ha participado en su negociación y no ha desempeñado un papel activo en la decisión de rescindirlo. Por consiguiente, el Tribunal Arbitral no da ningún consentimiento implícito a la extensión de la cláusula de arbitraje a [la Empresa Matriz] (2013, párr. 442) [traducción libre]. 
denciada a través de la participación directa en la ejecución del contrato ${ }^{63}$.

En este sentido, el tribunal arbitral rechazó la incorporación de la empresa $B$, en tanto que había quedado acreditado que esta fue una empresa durmiente durante la ejecución del contrato y que el envío del correo mencionado anteriormente había sido un error. Así, la falta de consentimiento es también confirmada por el propio comportamiento del señor $X$, quien, al recibir el correo de la empresa $B$, lo rechazó y solicitó explicaciones a la empresa $A$.

\section{CASO CCI No. 15372 (2009)}

Esta controversia surgió en relación con un contrato de compraventa de acciones celebrado por GTI S.A como comprador (demandante original) y Varig Logistic S.A. (Vlog o demandada 1) y Volo Do Brasil S.A. (Volo DB o demandada 2) como vende- dores respecto a las acciones de VRG Linhas aéreas S.A. (quien asumió la calidad de demandante después de suceder procesalmente a GTI S.A.).

GTI S.A (posteriormente VRG) inició un arbitraje contra Vlog, Volo DB (como partes signatarias del contrato de compraventa) y Volo Logistics LLC (Volo Logistics o demandado 3) y Matlinpatterson Global Opportunities Partners II L.P. (USA) y Matlinpatterson Global Opportunities Partners (CAYMAN) II L.P. A estas empresas (conjuntamente denominadas demandado 4), se les reclamó la aplicación del ajuste de precio de las acciones contenida en la cláusula 5.1 del contrato.

Como se puede apreciar en el siguiente cuadro, la demandada 4 controlaba a la demandada 3, la cual a su vez controlaba a la demandada 2 , quien controlaba a la demandada 1 , la cual, finalmente, previamente al contrato de compraventa, controlaba a la ahora demandante.

\section{Figura 2}

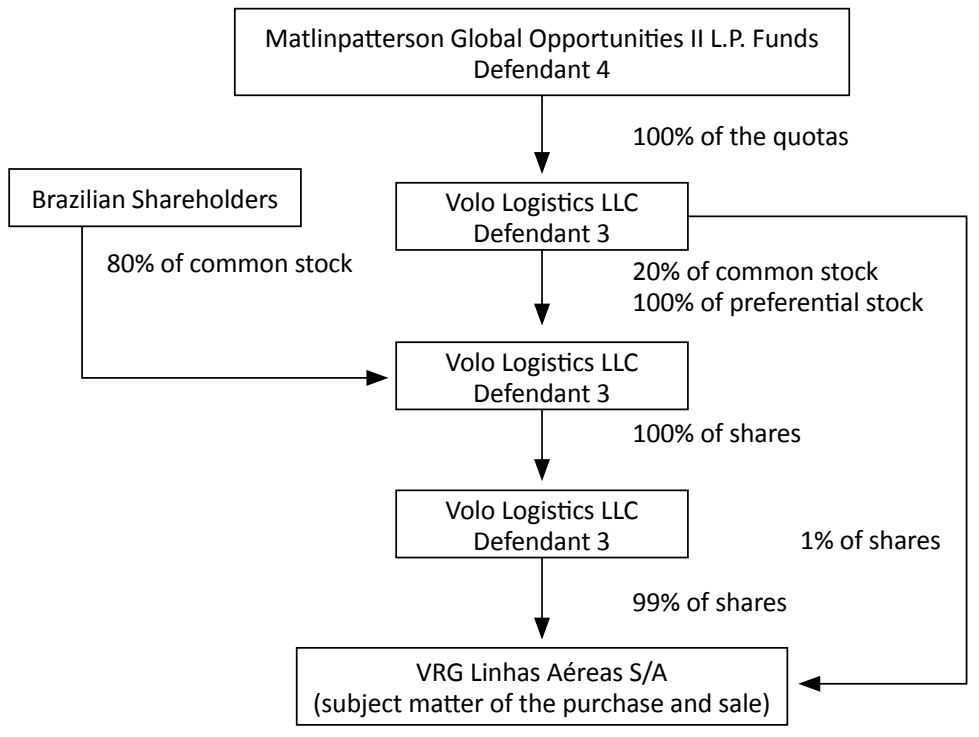

La demandada 3 y la demandada 4 se opusieron al arbitraje alegando que no habían firmado el contrato de compraventa de acciones.
En relación a la demandada 4, el tribunal arbitral concluyó que, al haber firmado la adenda 5 conjuntamente con el demandante, ésta había presta-

63 Al respecto, indicó:

La expresión 'teoría del grupo de sociedades' no es perfectamente exacta, ya que la ley francesa de arbitraje no acepta una teoría general de 'grupo de sociedades' tal como para abandonar la doctrina de la personalidad jurídica separada (...).Además, hay que señalar que, según la legislación francesa sobre arbitraje, 'no es tanto la existencia de un grupo lo que hace que las diversas sociedades del grupo queden vinculadas por el acuerdo firmado por una sola de ellas, sino más bien el hecho de que tal fue la verdadera intención de las partes'(...) "Parece que la intención mutua de las partes, tal como se evidencia por la implicación estrecha/directa del tercero en la ejecución del contrato, se está convirtiendo en el criterio decisivo para determinar si un acuerdo de arbitraje debe o no extenderse a ese tercero. Uno puede incluso preguntarse si la existencia de un grupo de empresas es realmente relevante (2008, párrs. 28-30) [traducción libre]. 
do su consentimiento a arbitrar, por lo que era una parte signataria del contrato y, en ese sentido, del convenio arbitral.

Respecto a la demandada 3, la demandante presentó dos teorías para solicitar su incorporación en el convenio arbitral: (i) la del consentimiento implícito; y (ii) la del levantamiento del velo societario. Para efectos del presente artículo nos limitaremos a comentar sobre la primera de estas teorías.

La demandante señalaba que la demandada 3 era parte del convenio arbitral pues (i) votó a favor de la aprobación del contrato de compraventa en la Junta General de Accionistas de la demandada 2 (parte signataria del contrato) y, además, (ii) tuvo una participación activa en la negociación del contrato, al enviar varios correos electrónicos y al ser parte de varias reuniones en las cuales el señor Lap Wai Chan, tuvo un rol destacado.

El tribunal arbitral rechazó el primer argumento de la demandante, señalando enfáticamente que no se puede considerar que un accionista se ve vinculado personalmente por las votaciones que pueda tener en la Junta General de una empresa en la que tiene acciones. Agregó, siguiendo una reducción a lo absurdo, que el argumento de la demandante llevaría a que todos los accionistas sean directamente parte de todos los convenios arbitrales contenidos en los contratos que firmen sus empresas con excepción de los que hayan votado en contra de la celebración de tales acuerdos ${ }^{64}$.
Por otro lado, el tribunal arbitral rechazó el segundo argumento de la demandante. Al entrar a revisar las pruebas, el tribunal arbitral se percató que el supuesto representante de la demandada 3, el señor Lap Wai Chan, quien habría preparado y presentado la estructura a ser ejecutada para la compraventa de acciones y determinó los términos del pago de cuotas, era en realidad, gerente de la demandada 4 y no de la demandada 3.

Asimismo, el tribunal arbitral sostuvo que incluso si las acciones tomadas por la demandada 4 (mencionadas en el párrafo anterior) fueran atribuibles a la demandada 3, no eran suficientes para considerar que esta última había manifestado tácitamente su consentimiento para ser parte del contrato $\mathrm{y}$, consecuentemente, del convenio arbitral contenido en éste.

El tribunal arbitral llegó a esta conclusión al considerar que es común en la práctica comercial que los gerentes de las empresas matrices participen en las negociaciones y, nominalmente, en la ejecución de los acuerdos adoptados por sus subsidiarias, no siendo posible inferir de dicha participación un consentimiento tácito de la empresa matriz de obligarse conjuntamente con su subsidiaria. Agregó, además, que en base a lo anterior podría llegarse a la conclusión exactamente contraria, y es que pese a haber participado en las negociaciones, la empresa matriz decidió no firmar el contrato, conducta de la cual se puede entender la intención de no querer verse obligada por él ${ }^{65}$.

64 En específico, se indicó:

Una cosa es votar como accionista a favor de la empresa en la que tiene una participación de capital firmando un contrato con una cláusula arbitral, y otra muy distinta es que el accionista se vea obligado personalmente como consecuencia de dicho voto. Volo Logistics limitó sus acciones a votar a favor de una propuesta de decisión de la empresa - no es posible deducir de ese voto la intención de someterse personalmente al acuerdo de arbitraje. El argumento del demandante, en una reducción al absurdo, haría que todos los accionistas estuvieran directa y personalmente sujetos a todos los acuerdos de arbitraje firmados por sus empresas, a menos que votaran en contra de la propuesta, una conclusión que es inaceptable en todos los aspectos (2009, párr. 89). [traducción libre].

Se indicó en el laudo:

Además, en opinión del Tribunal, no es posible inferir de las acciones llevadas a cabo por el demandado 4, que fueron atribuidas directamente al demandado 3, la intención tácita de Volo Logistics de aceptar el acuerdo y someterse al acuerdo arbitral. Es muy común en la práctica empresarial que los directivos de una empresa matriz participen en las negociaciones y, nominales, en la ejecución de un acuerdo adoptado por su subsidiaria. Además, es posible tener el entendimiento contrario si, a pesar de haber participado en las negociaciones, no firmó el acuerdo: la intención tácita que se puede inferir de esta conducta es que no quiso obligarse. Y que la otra parte en el contrato, consciente de la existencia de la empresa matriz, aceptó que ésta quedara exenta de responsabilidad (2009, párr. 86) [traducción libre]. 